\title{
Conformational Dynamics in Asymmetric Catalysis: Is Catalyst Flexibility a Design Element?
}

\author{
Jennifer M. Crawford \\ Matthew S. Sigman* \\ Department of Chemistry, University of Utah, 315 South 1400 East, \\ Salt Lake City, Utah 84112, USA \\ sigman@chem.utah.edu \\ Published as part of the 50 Years SYNTHESIS - Golden Anniversary Issue
}
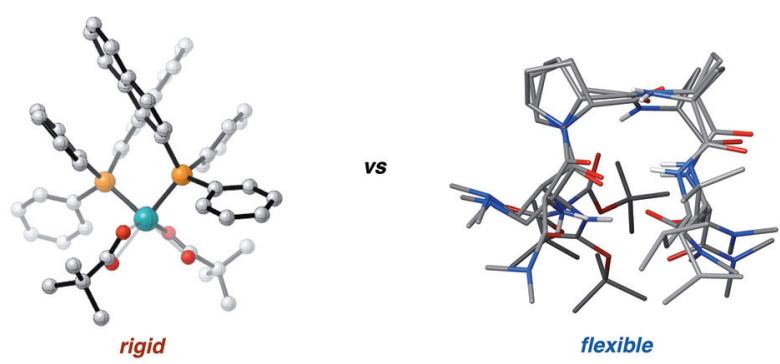

flexible

Rigidity is not a required design element for highly selective asymmetric catalysts

\author{
Received: 23.11 .2018 \\ Accepted: 28.11.2018 \\ Published online: 08.01 .2019 \\ DOI: 10.1055/s-0037-1611636; Art ID: ss-2018-z0788-sr \\ License terms: CC $0 \$$
}

Abstract Traditionally, highly selective low molecular weight catalysts have been designed to contain rigidifying structural elements. As a result, many proposed stereochemical models rely on steric repulsion for explaining the observed selectivity. Recently, as is the case for enzymatic systems, it has become apparent that some flexibility can be beneficial for imparting selectivity. Dynamic catalysts can reorganize to maximize attractive non-covalent interactions that stabilize the favored diastereomeric transition state, while minimizing repulsive non-covalent interactions for enhanced selectivity. This short review discusses catalyst conformational dynamics and how these effects have proven beneficial for a variety of catalyst classes, including tropos ligands, cinchona alkaloids, hydrogen-bond donating catalysts, and peptides.

Introduction

Tropos Ligands

Cinchona Alkaloids

Hydrogen-Bond Donating Catalysts

Peptide Catalysts

Conclusion

Key words asymmetric catalysis, non-covalent interactions, tropos ligands, organocatalysis, peptide catalysis, conformational dynamics

\section{Introduction}

Over the past billions of years, enzymes have evolved to be highly specific and efficient catalysts. The primary amino acid sequence folds into a tertiary (or quaternary) structure that orients the individual amino acid residues for optimal function, stabilizing transition states and intermediates through non-covalent interactions (NCIs). ${ }^{1}$ Enzymes (and other supramolecular catalysts), although they adopt a defined three-dimensional structure, are surprisingly flexible. ${ }^{2}$ In contrast to the initial 'lock and key' hypothesis ${ }^{3}$ for

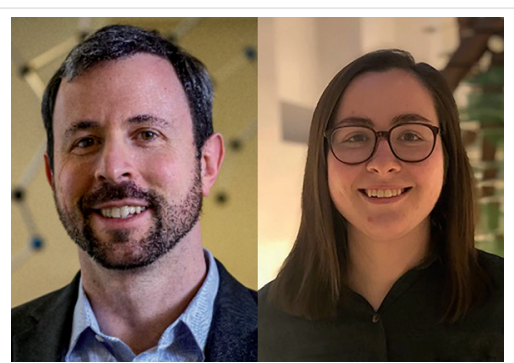

Matt Sigman (left) was born in Los Angeles, California in 1970. He received a B.S. in chemistry from Sonoma State University in 1992 before obtaining his Ph.D. in organometallic chemistry at Washington State University with Professor Bruce Eaton in 1996. He then moved to Harvard University to complete an $\mathrm{NIH}$-funded postdoctoral stint with Professor Eric Jacobsen. In 1999, he joined the faculty of the University of Utah where his research group has focused on the development of new synthetic methodology with an underlying interest in reaction mechanism. His research program explores the broad areas of oxidation catalysis, asymmetric catalysis, and the relationship between structure and function in complex reactions. He is currently the Peter J. Christine $S$. Stang Presidential Endowed Chair of Chemistry at the rank of Distinguished Professor.

Jennifer M. Crawford (right) was born in the Chicago area in 1994. She earned a B.A. in chemistry and mathematics from St. Olaf College in 2016 before beginning her Ph.D. studies at the University of Utah with Professor Matt Sigman. She is currently an NSF Graduate Research Fellow, and her research focuses on using modern physical organic tools to further understand the role of non-covalent interactions in asymmetric catalysis.

enzyme catalysis, more recent proposals (e.g., induced fit and conformational selection) rely on an enzyme's innate flexibility. ${ }^{2,4}$ Whether induced fit or conformational selection is more important for a particular enzymatic transformation, the key to either mechanism is the flexibility of the enzyme itself, leading to the preorganization of the active site and remarkable rate accelerations and selectivity. The 
active site's adaptability results in the stabilization of multiple intermediates and transition states throughout the catalytic cycle. . $^{1, c}$

In contrast, many traditional stereochemical models proposed for low molecular weight asymmetric catalysts, many of which have been inspired by enzymatic processes, invoke destabilizing steric interactions as the primary reason for observed selectivity. ${ }^{5}$ In fact, catalyst design in this field has historically focused on introducing rigid structural elements to prevent conformational flexibility. However, in recent years, attractive $\mathrm{NCI}$ have been proposed more and more frequently as stereocontrolling elements in asymmetric catalysis. ${ }^{6}$ This raises the scenario in which the use of catalysts with greater flexibility may be required to maximize the strength of attractive NCIs through reorganization of these highly distance and directionally sensitive interactions. ${ }^{7}$ The cooperative nature of these NCIs, whether attractive or repulsive, then defines a particular conformation that effectively relays chiral information from the catalyst to the substrate. ${ }^{\text {aa }}$ Multiple NCIs can achieve this preorganization by working in concert, much in the same way that enzymes function. ${ }^{1 a, 6 a}$ In other words, the catalyst could adapt to provide stabilization of the desired diastereomeric transition state leading to an enantioenriched product, while minimizing steric repulsion - a very different design element than the historical strategies in asymmetric catalyst development. Thus, catalyst flexibility can lead to stabilized intermediates and transition states throughout the catalytic cycle by engaging in a variety of NCIs akin to enzymes.

It is becoming increasingly clear that far from being detrimental, conformational flexibility in a low molecular weight catalyst can be beneficial and lead to high levels of selectivity. Additionally, this scenario could also allow for broad substrate compatibility as the small molecule dynamic catalysts are more likely to be capable of adapting to a substrate's size and shape. The purpose of this short review is to highlight a variety of catalyst classes used in asymmetric catalysis that benefit from conformational flexibility.

\section{Tropos Ligands}

Atropos ligands are defined by the presence of an axis of chirality. ${ }^{8}$ These ligands, especially 2,2'-bis(diphenylphosphino)-1,1'-binaphthyl (BINAP), have been used with great success and have been classified as a 'privileged' catalyst class. ${ }^{9}$ Their rigid backbone is frequently invoked in quadrant blocking stereochemical models that explain the experimentally observed selectivity. For example, in 1987, Noyori and coworkers reported the hydrogenation of $\beta$-keto esters to afford chiral $\beta$-hydroxy esters using a Ru(II)-BINAP catalyst (Scheme $1 \mathrm{~A}) \cdot{ }^{10}$ Following the crystallization of the catalyst, it was shown that the chiral information from the rigid BINAP backbone was relayed to the phenyl substituents of phosphorous, resulting in the conformation shown in Scheme $1{ }^{11}$ This conformation 'blocks' two of the quadrants of the coordination sphere through steric repulsion. Consequently, the favored diastereomeric transition state is proposed to be the one that allows the ketone to approach an open quadrant. In contrast to the high rotation barrier associated with 1,1'-bi-2-naphthol (BINOL) or BINAP catalysts, ${ }^{12}$ tropos ligands, such as 2,2'-bis(diphenylphosphino)biphenyl (BIPHEP), are characterized by a low barrier of rotation about their axis of chirality, resulting in a racemic or scalemic mixture (Scheme 1B). ${ }^{13}$ Because the axis of chi-

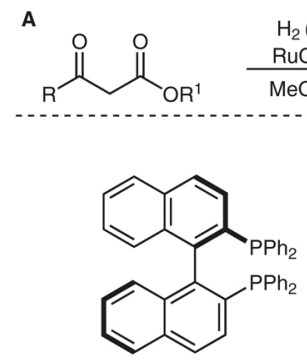

(R)-BINAP

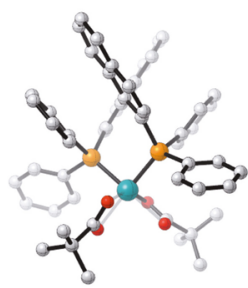

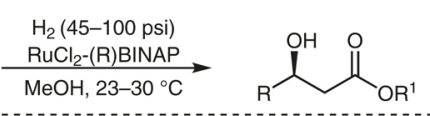

B
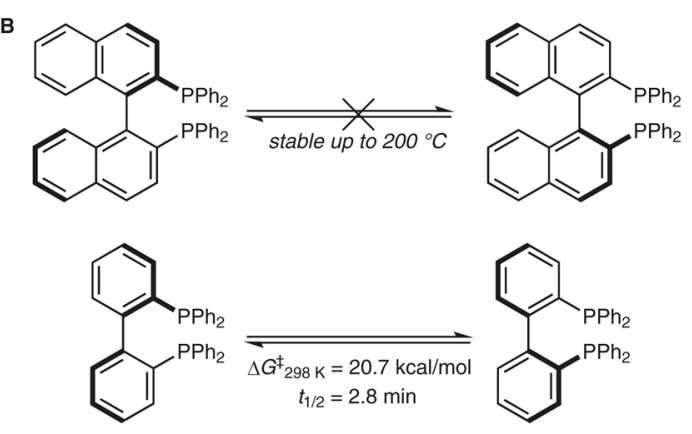

(1)
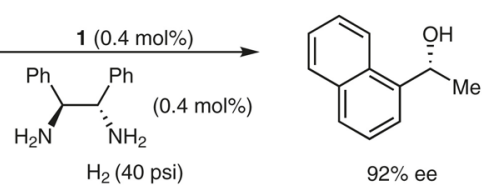

$\mathrm{KOH}(0.8 \mathrm{~mol} \%)$

2-propanol, $-35^{\circ} \mathrm{C}, 12 \mathrm{~h}$

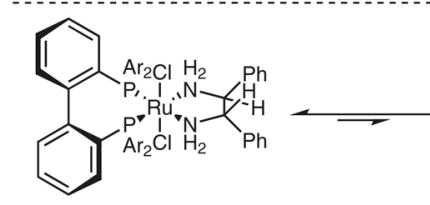

$\left(S_{a x i a l}, S, S\right)-1$

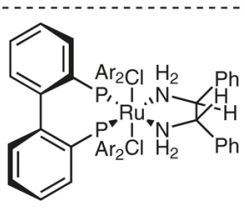

$\left(R_{\text {axial }}, S, S\right)-1$
Scheme 1 (A) BINAP blocks two of the four quadrants, controlling the trajectory of the $\beta$-keto ester. (B) Tropos ligands can readily racemize at room temperature through $\sigma$-bond rotation whereas atropos ligands cannot. (C) Chiral activation is an effective strategy that enables the use of tropos ligands for asymmetric hydrogenation 
rality is dynamic, it is possible to perturb the racemic mixture towards favoring one enantiomer or the other through either catalyst activation or deactivation. ${ }^{13 \mathrm{~b}, 14}$

For example, Mikami et al. developed a strategy to use tropos ligands in the presence of a chiral activator that induces a conformational shift towards one diastereomer because of the flexible nature of the BIPHEP backbone. ${ }^{15}$ For instance, in the Ru-catalyzed enantioselective hydrogenation of ketones, the presence of (S,S)-1,2-diphenylethylenediamine results in the formation of a 3:1 diastereomeric ratio of $\left(S_{\text {axial }}, S, S\right)-\mathbf{1}$ to $\left(R_{\text {axial }}, S, S\right)-\mathbf{1}$ (Scheme $\left.1 C\right)$. This strategy relies on the major diastereomer reacting faster than the minor isomer. Thus, the use of a stereochemically flexible, achiral ligand in the presence of a chiral activator leads to a highly enantioenriched product (up to $92 \%$ ee).

In a similar fashion, Trapp and Storch developed a Rhcatalyzed enantiodivergent asymmetric hydrogenation of prochiral $(Z)-\alpha$-acetamidocinnamates and $\alpha$-substituted acrylates (Scheme 2). ${ }^{16}$ This process relies on the flexible nature of a BIPHEP derivative, which can easily racemize at room temperature. ${ }^{13 \mathrm{c}}$ By using $(S)$-naproxen as a chiral auxiliary, the conformational preference of the flexible tropos ligand is shifted. The equilibrium can be further perturbed when the temperature is changed, allowing for the possibility of an enantiodivergent transformation. In fact, heating the diastereomeric mixture results in conversion into the $\left(S_{\text {axial }}, S, S\right)$-diastereomer in greater than $98 \%$ purity $(<1: 99$ $\mathrm{dr})$, whereas at low temperatures the $\left(R_{\text {axial }}, S, S\right)$-diastereomer is favored $(61: 39 \mathrm{dr}){ }^{16}$
Upon formation of a metal complex, the flexible tropos ligands can no longer freely rotate. The already established equilibrium composition is then transferred to the metal complexes. These complexes can subsequently be used for asymmetric hydrogenation. The $(S)$-product can be obtained in up to $98 \%$ ee whereas the $(R)$-product is obtained in a maximum of $74 \%$ ee (Scheme 2). Thus, Trapp and Storch used the flexible nature of BIPHEP-type ligands to perturb the equilibrium through the use of a chiral auxiliary, followed by freezing this equilibrium through complexation to develop an enantiodivergent asymmetric hydrogenation that affords both natural and unnatural amino acid derivatives in high enantiomeric purity. More recent work by Trapp and coworkers demonstrated that a similar approach could be used in a temperature-controlled enantiodivergent iridium-catalyzed asymmetric hydrogenation of $\alpha$-substituted acrylic acids to afford $\alpha$-substituted propionic acids. ${ }^{17}$

Again, changing the temperature induced a conformational change of the flexible tropos ligand. This in turn led to either enantiomer of the product depending on the reaction conditions. In these cases, the flexible nature of BIPHEP allows for the development of these enantiodivergent transformations.

Moreover, as Diéguez and coworkers have shown, the flexibility of tropos ligands has proven beneficial for a variety of Pd-catalyzed allylic substitutions because the flexible backbone can accommodate both hindered and unhindered substrates. ${ }^{18,19}$ They have shown that phosphite, phospho-

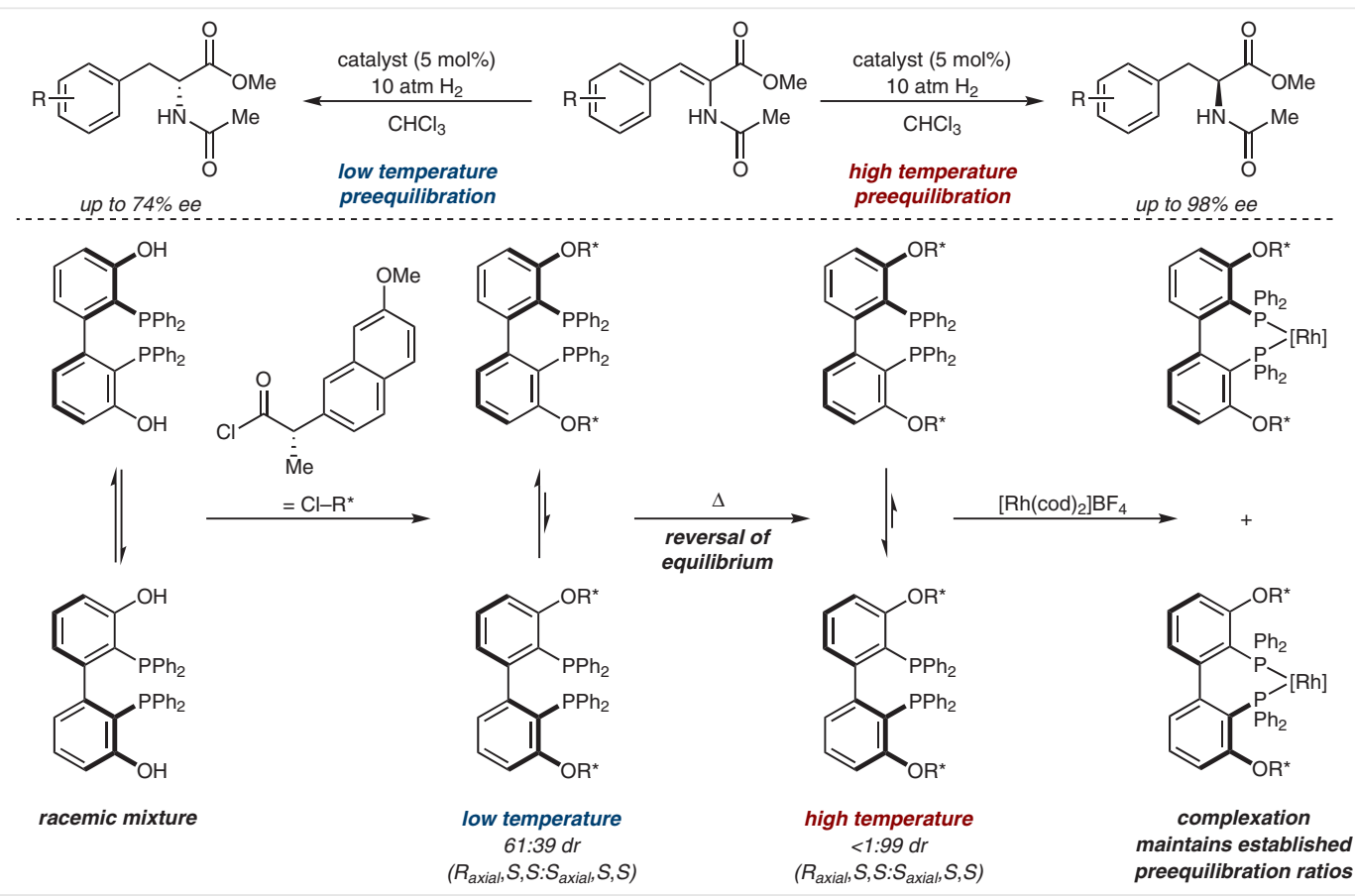

Scheme 2 Preequilibration of a tropos ligand followed by complexation for a temperature-dependent enantiodivergent hydrogenation 
roamidite, and phosphite-thioether tropos ligands are quite effective. ${ }^{18,19 c}$ For example, phosphite-oxazoline tropos ligands such as $\mathbf{2}$ were developed for the allylic substitution of three sterically different substrate classes including $\mathbf{3 a - c}$ (Scheme 3A). ${ }^{20}$ Beyond the fact that the use of phosphite ligands increases reaction rates over phosphines, the flexible

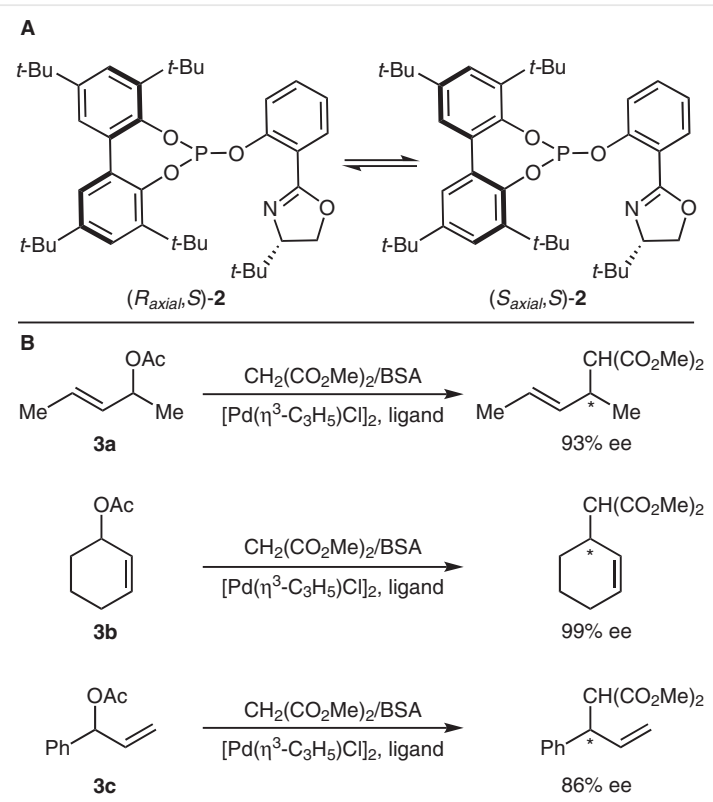

Scheme 3 (A) One example of a tropos phosphite-oxazoline ligand used for palladium-catalyzed allylic substitutions. (B) Three sterically diverse substrates were used biphenyl backbone of the ligand increases catalyst adaptability. Only the tropos phosphite-oxazoline ligand performed well with high yields and enantioselectivities for the three representative substrates as compared to other commonly used ligands including PHOX, Trost's, and Pfaltz's ligands. ${ }^{20,21}$ Additional work focused on elucidating the conformational preferences of this tropos ligand to further understand the underlying reasons for the expanded substrate scope observed for this ligand class. Through DFT calculations, NMR studies, and expanding the scope to include more challenging reaction partners, the authors concluded that the active tropos ligand $\mathbf{2}$ assumes an $\left(S_{\text {axial }}, S\right)$ configuration upon coordination, but the ligand remains relatively flexible (Scheme 3B). ${ }^{19 a}$ The balance of rigidity and flexibility leads to high enantioselectivity for sterically diverse substrates.

Diéguez and coworkers also developed phosphite-thioether ligands derived from carbohydrates for palladiumcatalyzed allylic substitution. ${ }^{19 b}$ Historically, bidentate P-S ligands have suffered from low substrate generality and difficulty controlling the thioether configuration..$^{22}$ However, the authors had had previous success with D-xylose-derived phosphite-thioether ligands such as $\mathbf{4}$ and $\mathbf{5}$ (Scheme 4). ${ }^{19 \mathrm{~b}}$ The highly modular nature of these ligands allowed the authors to evaluate 204 ligands representing four different stereoisomers. ${ }^{19 \mathrm{~d}}$ These ligands were designed through modifying the furanoside portion of the ligand by inverting the absolute configuration at $\mathrm{C} 3$ and changing the position of the thioether to either C3 or C5. Using this library, they identified ligands that could form $\mathrm{C}-\mathrm{C}, \mathrm{C}-\mathrm{N}$, and $\mathrm{C}-\mathrm{O}$ bonds

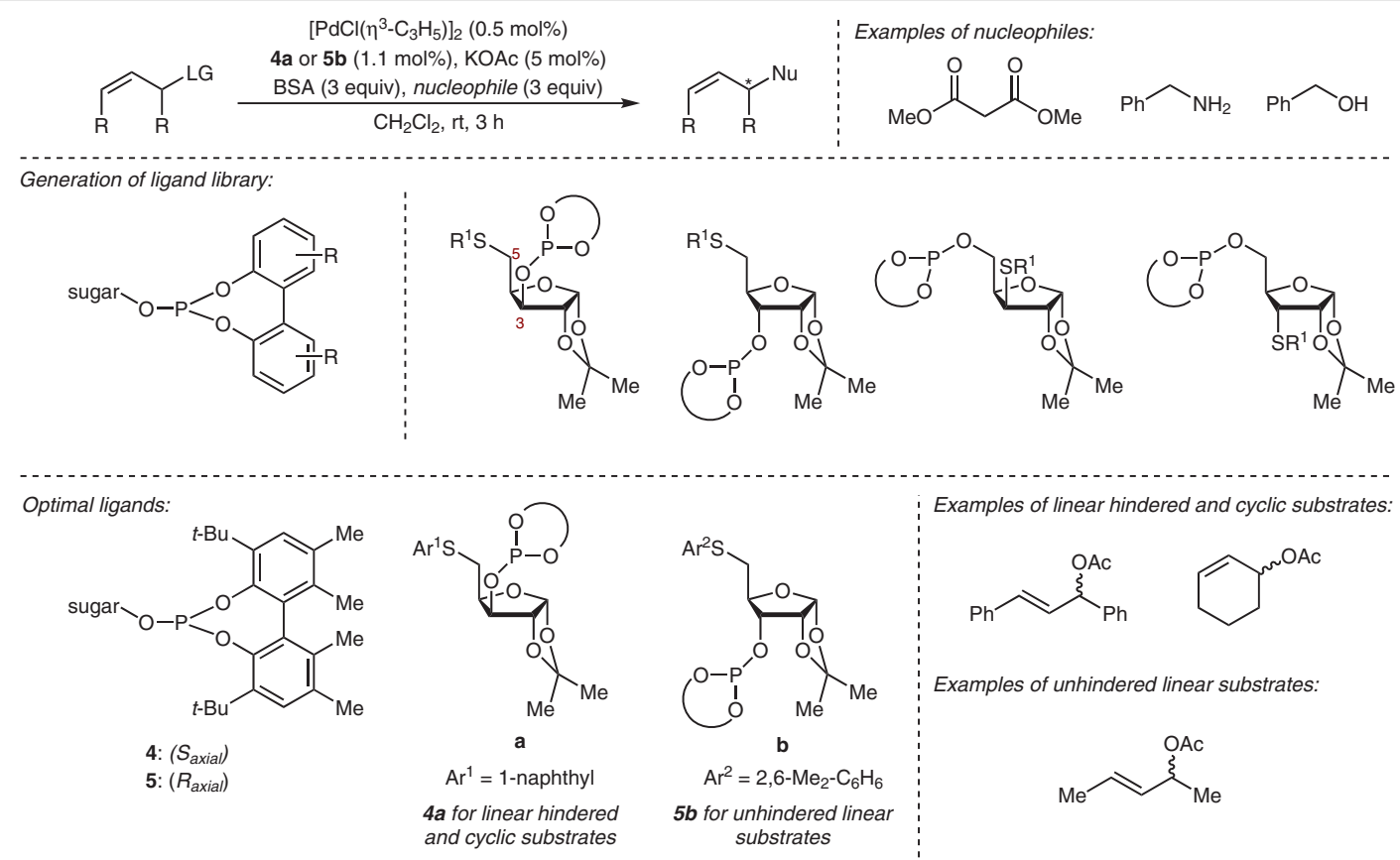

Scheme 4 A library of 204 phosphite-thioether ligands was designed and evaluated in a palladium-catalyzed allylic substitution reaction 
for hindered and unhindered substrates alike (e.g., see Scheme 4) with high levels of selectivity (up to $>99 \%$ ee). Again, the broad substrate scope, including both cyclic and acyclic substrates, resulting from the use of this ligand class likely results from the conformational flexibility of the phosphinite biphenyl backbone.

Flexible ligands bound to transition metals or the combination of a rigid, chiral ligand and flexible, achiral ligand can lead to excellent levels of selectivity. One reason for the effectiveness of tropos ligands is that the substrate (or chiral additive) can induce a conformational change in the ligand, leading to an adaptable yet defined chiral pocket. As a result, these ligands can display greater substrate generality because the chiral pocket can adapt to the steric demands of the substrate. Therefore, in these examples, conformationally dynamic tropos ligands can give unique advantages for method development.

\section{Cinchona Alkaloids}

The first use of a cinchona alkaloid for asymmetric catalysis was by Bredig and Fiske in 1912 for the addition of HCN to benzaldehyde. ${ }^{23}$ Although the resulting cyanohydrin was only obtained in modest ee, this was the first hint that these natural products could be used in asymmetric catalysis. Since then, cinchona alkaloids such as quinine, quinidine, and their derivatives have been successfully used in metal, phase-transfer, nucleophilic, base, and cooperative asymmetric catalysis. ${ }^{24}$ Hence, these scaffolds have been recognized as a privileged catalyst class. ${ }^{9 b, 24 b}$ Although at first glance it seems that cinchona alkaloids are quite rigid, they can indeed adopt multiple, distinct conformations in solution. ${ }^{25}$ The flexibility primarily arises from free rotation

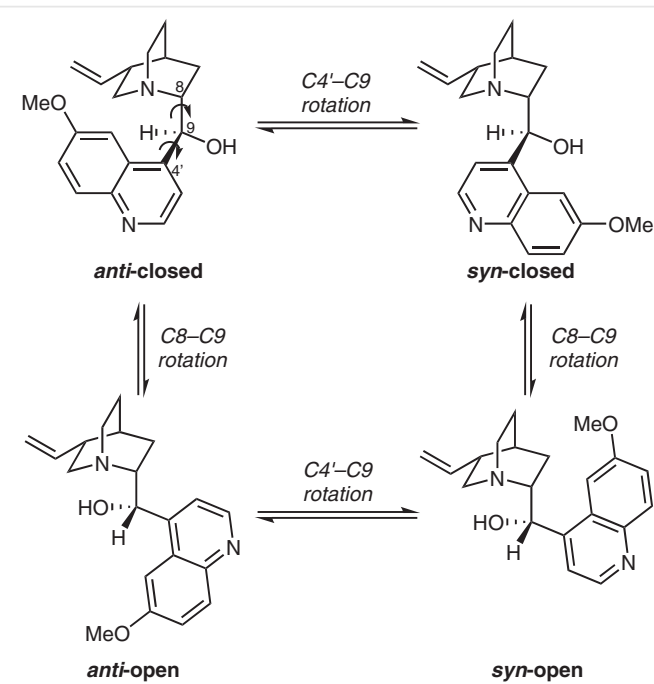

Scheme 5 Four accessible conformations of quinidine. There have been up to 7 major conformations reported in the literature about the C8-C9 and C4'-C9 bonds, giving rise to four major conformations in solution (Scheme 5)..$^{25,26}$ Upon solvation or substrate binding, the conformational population shifts to favor one conformer, although the other conformers generally remain energetically accessible under a Curtin-Hammett scenario. ${ }^{27}$ One concern for using flexible catalysts is that these other observed conformations could stabilize transition states leading to the minor enantiomer, resulting in an overall less selective transformation. ${ }^{28}$

Because of the complications associated with conformational flexibility, a general strategy to improve the activity of a cinchona alkaloid catalyst is to rigidify the scaffold or otherwise control the conformation. For example, quinine and quinidine are used in the Sharpless dihydroxylation as ligands for osmium, but catalytic activity is improved upon constraining the conformation such that a more defined binding pocket is formed, better orienting the substrate for enantioselective dihydroxylation. ${ }^{29}$ Additionally, Hoffmann and coworkers synthesized oxazatwistanes such as $\mathbf{6}$ that lock quinine or quinidine in an anti-open conformation. ${ }^{30} \mathrm{~A}$ second method for constraining the conformation replaces the hydroxy group at C9 with fluorine to favor a syn-open conformation through the gauche effect. ${ }^{31}$

Although imparting rigidity to cinchona alkaloids has been an effective strategy, more recent work by Deng and coworkers highlights that in certain cases more flexible cinchona alkaloid derivatives can outperform a rigid catalyst such as 6. In 2004, they reported the cinchona-alkaloid-catalyzed conjugate addition of malonate and $\beta$-ketoesters to nitroalkenes (Scheme 6A). ${ }^{32}$ Even though catalyst 7 is more flexible than catalyst $\mathbf{6}$, with free rotation about C8-C9, higher enantioselectivities were observed. Additional catalyst optimization revealed that cinchonine $\mathbf{8}$ performs better than cinchonidine 7 ( $-96 \%$ ee vs $93 \%$ ee), which is more selective than the more rigid analog 6. Preliminary results from mechanistic experiments suggested that the cinchona alkaloids $\mathbf{7}$ and $\mathbf{8}$ act in a bifunctional manner with the quinoline hydroxy group and the quinuclidine nitrogen functioning to stabilize an organized transition state (Scheme 6B).

Later work expanded upon the conjugate addition of malonates to nitroalkenes to generate tertiary stereocenters adjacent to a quaternary stereocenter (Scheme 6C). ${ }^{33}$ Building on their previous work, ${ }^{32}$ Deng and coworkers hypothesized that their previously successful cinchona alkaloid derivative $\mathbf{9}$ would allow for the enantio- and diastereoselective addition of a trisubstituted Michael donor to a nitroalkene. ${ }^{33}$ They sought to identify the active conformation and develop transition state models of their quinineand quinidine-derived catalysts through mechanistic studies. Based on the absolute configuration of the product, first-order dependence on catalyst, alkene, and Michael donor, and poor performance in polar protic solvents, they concluded that the catalyst acts in an acid-base bifunctional mode with key hydrogen-bonding interactions between 
the catalyst and substrate. They also compared the results using catalyst 9 to the results using conformationally constrained catalyst 10. Ultimately, they discovered that the rigid catalyst analogue, which is locked in an anti-open conformation, displayed very similar diastereo- and enantioselectivities to catalyst $\mathbf{9}$ (e.g., see Scheme 6 ), suggesting that the active conformation is likely anti-open. Both of these catalysts are highly effective for a broad range of trisubstituted Michael donors and nitroalkenes.

Additionally, Deng and coworkers have developed methods for the enantioselective alcoholytic desymmetrization of meso anhydrides using cinchona alkaloid catalysts (Scheme 7). ${ }^{34}$ This includes the methanolysis of cis-2,3-dimethyl succinic anhydride, which was used for mechanistic studies of this type of reaction. ${ }^{35}$ They determined that this
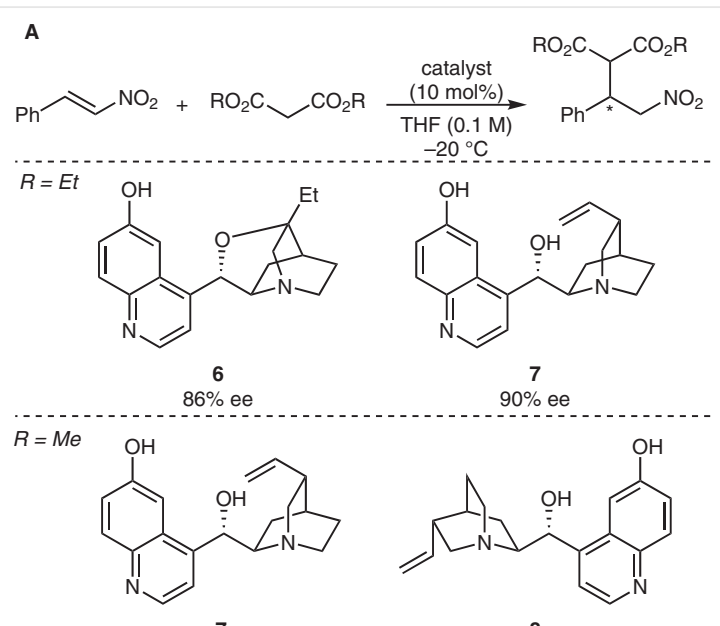

7

$90 \%$ ee
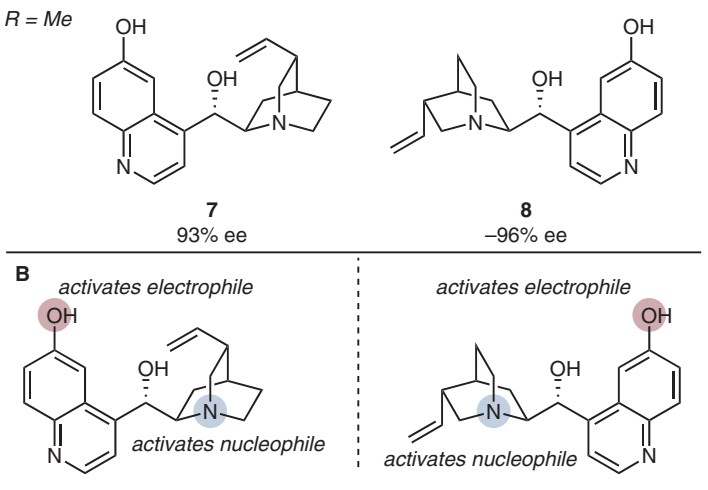

8
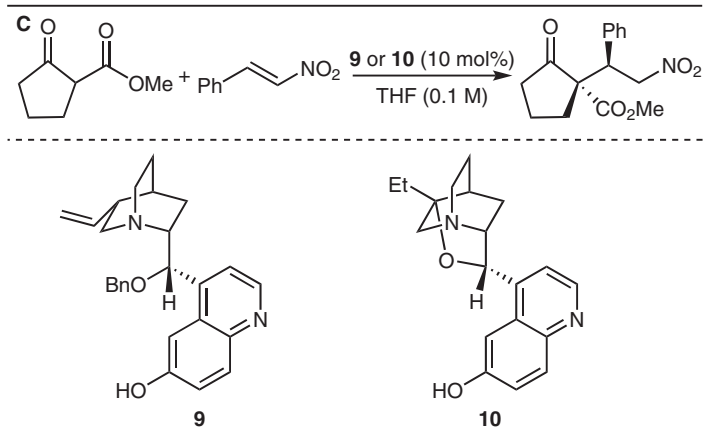

$94: 6 \mathrm{dr},>99 \%$ ee

$97: 3 \mathrm{dr}, 98 \%$ ee

Scheme 6 (A) Comparison of rigid and flexible catalysts. (B) Bifunctional activation of both substrates using a quinidine or quinine catalyst. (C) The active conformation for the conjugate addition of malonates to nitroalkenes was identified using a conformationally locked catalyst

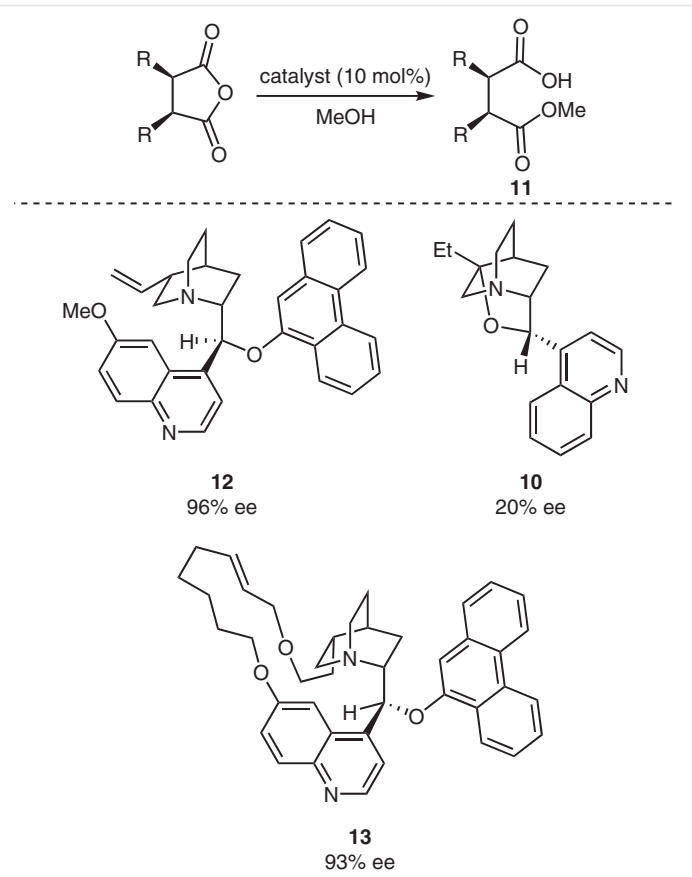

Scheme 7 A newly synthesized rigid cinchona alkaloid derivative was used to identify the active conformation for the methanolysis of mesosuccinic anhydride

transformation proceeds via general base catalysis wherein the alcohol is activated by the quinuclidine nitrogen through the formation of a hydrogen-bonding complex between the catalyst and substrate alcohol. Subsequently, the alcohol reacts selectively with one of the carbonyl groups of the anhydride, affording an enantioenriched product such as 11. They next sought to identify the active catalyst conformation. Based on their previous successes with rigid cinchona alkaloid analogues $\mathbf{6}$ and $\mathbf{1 0}$, they attempted to probe the conformation using anti-open locked catalyst 10.30,32,33 However, the enantioselectivity was dramatically affected when switching from 12 to $\mathbf{1 0}$, resulting in a decrease from $96 \%$ ee to $20 \%$ ee. They then designed a cinchona alkaloid derivative 13 that would be locked in a syn-closed conformation through a macrocyclic ring. ${ }^{35}$ This catalyst affords desymmetrized product 11 in comparable enantioselectivities to the original catalyst $\mathbf{1 2}$ (93\% vs $96 \%$ ee, respectively), confirming that the active catalyst conformation for the stereodetermining step adopts a syn-closed conformation. Because different conformations are active for the cinchonaalkaloid-catalyzed conjugate addition versus alcoholysis of meso anhydrides, it is possible that the generality of cinchona alkaloid catalysts arises from different conformations being catalytically active under altered conditions.

Most frequently, cinchona alkaloid scaffolds are made more rigid for applications in highly selective asymmetric catalysis, but the importance of conformational dynamics should not be overlooked. Although there are only limited 
examples where the inherent flexibility of cinchona alkaloids is invoked as an important factor in selectivity, it is possible, and indeed likely, that conformational dynamics play a role in adapting to the steric demands of a variety of substrates and stabilizing intermediates and transition states through multiple, cooperative NCIs.

\section{Hydrogen-Bond Donating Catalysts}

Dual hydrogen-bond donor (HBD) catalysts, such as chiral urea and thiourea derivatives, have also emerged as a privileged catalyst scaffold over the past twenty years. ${ }^{9 b, 36}$ These catalysts generally function by activating electrophiles through hydrogen bonding (often through anion binding) and have been used in mechanistically diverse transformations. ${ }^{37}$ Although HBD catalysts are frequently designed to be relatively rigid, Nagasawa and coworkers have synthesized effective catalysts that incorporate flexible alkyl chains. These chiral, guanidine-based catalysts possess two thiourea portions and include either methylene or ethylene linkers such as in $\mathbf{1 4}$ and $\mathbf{1 5}$ (Scheme 8A). ${ }^{38}$ Due to their flexibility, these catalysts have been shown, through Eyring analysis, to control reaction outcomes primarily through entropy rather than enthalpy.

For example, Nagasawa and coworkers reported an enantiodivergent Mannich-type reaction in 2010 (Scheme $8 \mathrm{~B}){ }^{39}$ Since the conformation of the highly flexible catalyst 16 should be different in polar compared to nonpolar solvents, the authors hypothesized that this type of thiourea catalyst could be used for an enantiodivergent process dependent on the reaction solvent. In nonpolar solvents like $m$-xylene, the $(S)$-product is obtained whereas the $(R)$ product is favored when aprotic polar solvents such as acetonitrile are used.

They also observed a positive correlation between temperature and selectivity. Although in many asymmetric processes, decreasing the temperature leads to enhanced selectivity, in this case, increasing the temperature (from $10{ }^{\circ} \mathrm{C}$ to $0^{\circ} \mathrm{C}$ ) in nonpolar solvents led to an increase in selectivity. Interestingly, the anticipated temperature trend (low temperature leads to high selectivity) occurred in polar solvents. This unexpected result prompted an Eyring analysis ${ }^{40}$ by measuring the enantioselectivity as a function of temperature (Scheme 8C). This demonstrated that a compensating effect between the differential enthalpy $\left(\Delta \Delta H^{\ddagger}\right)$ and differential entropy of activation $\left(\Delta \Delta S^{\ddagger}\right)$ exists. ${ }^{39}$ In the nonpolar case, each term is positive suggesting that the positive $\Delta \Delta S^{\ddagger}$ value offsets the unfavorable enthalpic requirements. In acetonitrile, both terms are negative; thus, enthalpy remains an important stereocontrolling element. Therefore, the conformational flexibility of this chiral guanidine/bisthiourea organocatalyst is likely the underlying reason for the observed high selectivity for either enantio-

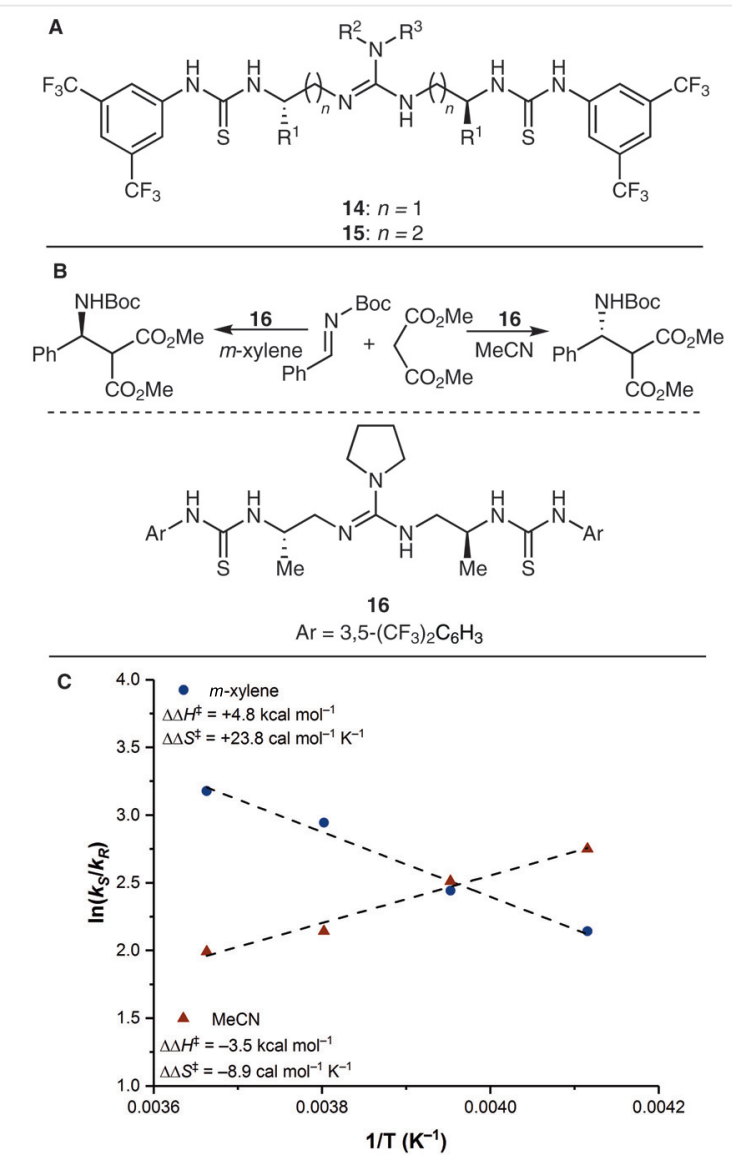

Scheme 8 (A) Highly flexible thiourea catalysts were used for the (B) highly selective enantiodivergent Mannich reaction, and (C) Eyring analysis revealed the importance of entropy as compared to enthalpy

mer. In other systems employing these conformationally flexible HBD catalysts, entropy remains a major stereocontrolling element.

Furthermore, Nagasawa and coworkers utilized entropy to control 1,4- and 1,2-type Friedel-Crafts reactions between phenol derivatives and organic electrophiles with $\mathbf{1 8}$ and 19, respectively. (Schemes $9 \mathrm{~A}$ and $10 \mathrm{~A}$ ). ${ }^{41}$ In the case of the 1,4-type Friedel-Crafts addition, as observed for the enantiodivergent Mannich reaction described above, ${ }^{39}$ an increase in temperature resulted in an accompanying enhancement in enantioselectivity $\left(80 \%\right.$ ee at $0{ }^{\circ} \mathrm{C}$ to $85 \%$ ee at $\left.20^{\circ} \mathrm{C}\right) .{ }^{41 \mathrm{~b}}$ For this reaction, it is also important to note that the more flexible ethylene-tethered catalyst $\mathbf{1 8}$ is significantly more selective than $\mathbf{1 7}$ (91\% ee vs $34 \%$ ee, Scheme 9A). Subsequent Eyring analysis revealed that irrespective of concentration, both the differential enthalpy and entropy of activation are positive. ${ }^{41 \mathrm{~b}}$ In fact, at a concentration of $0.025 \mathrm{M}$, the enthalpic measure reaches zero whereas the differential entropy of activation is $6.1 \mathrm{cal} \mathrm{mol}^{-1} \mathrm{~K}^{-1}$. This means that at this concentration, entropy is likely the only contributor to $\Delta \Delta G^{\ddagger}$ (Scheme 9B). The practical conse- 


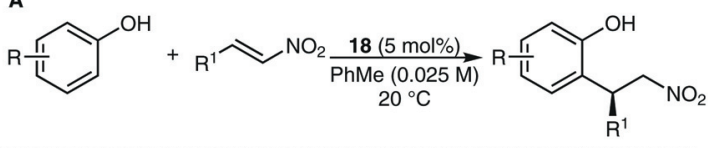

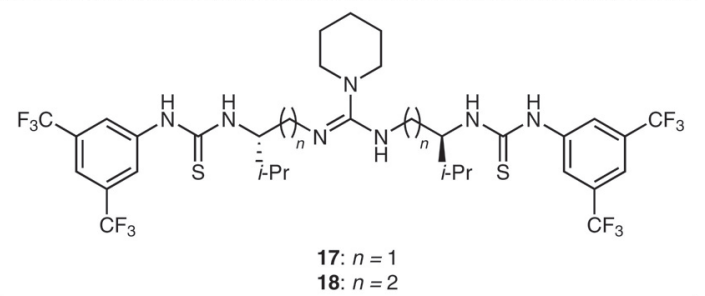

B<smiles>O=[N+](C=C[Pb])C=C[Pb]</smiles>

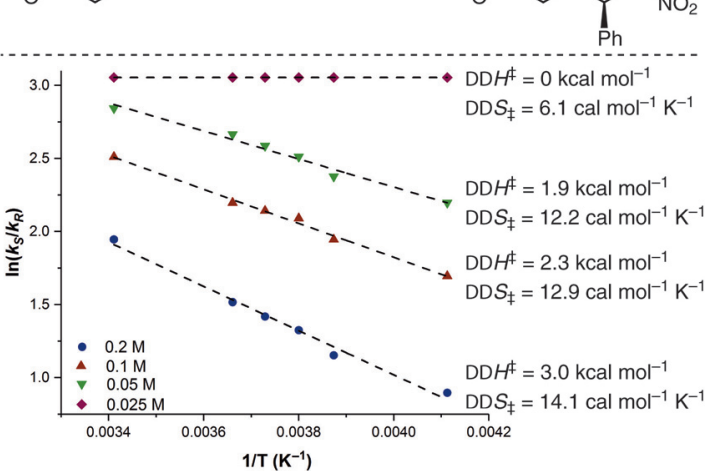

Scheme 9 (A) A highly selective 1,4-type Friedel-Crafts reaction was developed that uses (B) a conformationally flexible catalyst, and (C) is predominantly entropy controlled as shown through Eyring analysis quence of entropy-controlled asymmetric transformations is that they can be performed at easily accessible temperatures without compromising selectivity. Theoretically, it raises the question of what the role of conformational dynamics is for an entropically controlled process.

Nagasawa and coworkers sought to determine the connection between conformational dynamics and entropycontrolled reactions while studying the 1,2-type FriedelCrafts reaction between phenols and $\mathrm{N}$-Boc-imines catalyzed by 19 (Scheme $10 \mathrm{~A}){ }^{41 a}$ Following optimization of the reaction conditions, their mechanistic studies began with an Eyring analysis ${ }^{40}$ to identify the differential enthalpic and entropic activation parameters.

However, unlike the 1,4 -Friedel-Crafts reaction, ${ }^{41 \mathrm{~b}}$ in this case, an inversion temperature was observed $\left(T_{i n v}=\right.$ $21.7^{\circ} \mathrm{C}$, Scheme 10B). ${ }^{42}$ Enantioselectivity increased with temperature from $-20{ }^{\circ} \mathrm{C}$ to $20^{\circ} \mathrm{C}$, yet further temperature increase led to a decrease in enantioselectivity. ${ }^{41 a}$ These interesting experimental results were accompanied with brief computational analysis of the likely transition state(s). By computing model systems, they ultimately proposed a structural model wherein the transition state leading to the major enantiomer has the imine hydrogen-bonded to both
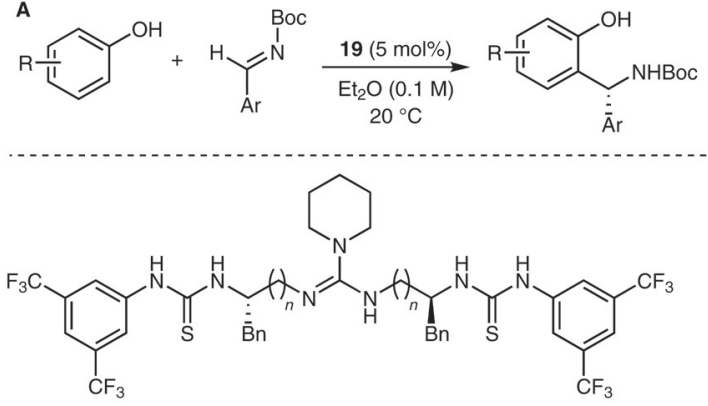

19: $n=2$
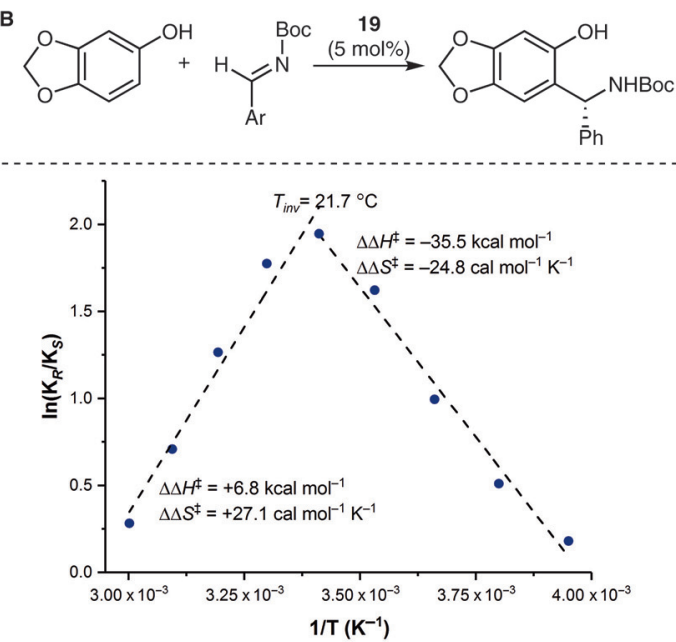

Scheme 10 (A) A highly selective 1,2-type Friedel-Crafts reaction. (B) An inversion temperature was observed following Eyring analysis, confirming the importance of entropy

the guanidinium and thiourea and the phenoxide anion interacts with the second thiourea moiety. However, the transition state geometry is likely different from the catalyst's ground state conformation. The authors propose that this hypothesized conformational shift occurs upon substrate binding and may explain the important entropic activation parameter. Thus, conformational dynamics play an important role in the entropy control observed in this transformation.

Although the HBD catalysts used by Nagasawa and coworkers are quite flexible, many thiourea catalysts are designed to be rigid. ${ }^{36 a, 38 a}$ Even though the chiral scaffold itself is relatively inflexible, HBD catalysts have been shown to stabilize reactive intermediates and transition states alike through a ternary complex. ${ }^{43}$ In 2009 , Jacobsen and Klausen reported an enantioselective thiourea and benzoate co-catalyzed Pictet-Spengler cyclization (Scheme 11A) ${ }^{44}$ The authors sought to determine the mechanism because of the generality and synthetic utility of this transformation. ${ }^{43}$ In conjunction with mechanistic experiments, computations were also performed on each proposed intermediate and transition state in the absence and presence of the thiourea 


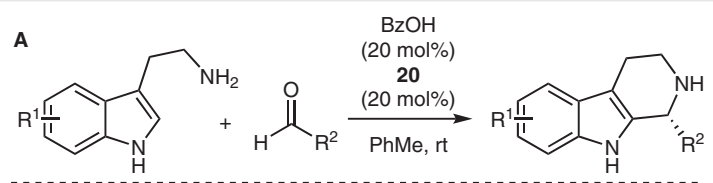

$$
\text { 年) }
$$

Scheme 11 (A) A benzoic acid and thiourea co-catalyzed enantioselective Pictet-Spengler transformation. (B) The thiourea co-catalyst. (C) Important non-covalent interactions that stabilize the transition state for rearomatization, the enantiodetermining step

co-catalyst 20 (Scheme 11B). These computations revealed that the presence of the thiourea catalyst lowers the energy of each reactive intermediate and transition state as compared to when benzoate was used alone. The ability of the thiourea catalyst to bind anions and the cooperative nature of multiple $\mathrm{CH}-\pi$ and $\mathrm{H}$-bonding interactions between the co-catalysts and substrate provides this stabilization. Although the thiourea catalyst used is quite rigid, the ability of the thiourea to stabilize all intermediates and transition states in the presence of the benzoate and substrate through NCIs (e.g., see Scheme 11C) suggests some catalyst adaptability is important for reorganizing to stabilize these diverse structures throughout the catalytic cycle.

It has previously been demonstrated that NCIs are important stereocontrolling elements for HBD catalysts. ${ }^{6 a}$ Beyond NCIs between catalyst(s) and substrate, it is also apparent that entropy can be important for selectivity as is the case for Nagasawa's chiral thiourea catalysts. ${ }^{39,41}$ With some flexibility, it is likely that a HBD catalyst is able to maximize the strength of multiple, cooperative NCIs and adapt to stabilize intermediates and transition states for highly effective catalysis. ${ }^{43}$ In each case, flexibility can facilitate effective asymmetric catalysts rather than be a detrimental factor.

\section{Peptide Catalysts}

Beginning with proline in the Hajos-Parrish-Eder-Sauer-Wiechert reaction, ${ }^{45}$ amino acid derived catalysts have been used as highly selective asymmetric catalysts. Over the past twenty years, peptide catalysts, generally composed of three to four amino acids, have been used with high levels of regio-, chemo- and stereoselectivity in a diverse array of transformations. ${ }^{46}$ Given their success, peptides can be classified as one type of privileged catalyst structure despite the fact that, unlike most other privileged catalysts, peptides are inherently flexible. ${ }^{9 b, 47}$ One successful strategy for effective catalysis is to induce a defined secondary structure through careful choice of the amino acid sequence. For example, one commonly found motif is a DPro/Xaa- or Pro/Xaa-containing sequence, where Xaa is usually an achiral $\alpha, \alpha$-disubstituted amino acid that induces a $\beta$-turn which is stabilized through intramolecular hydrogen bonding. ${ }^{48}$ Although a $\beta$-turn motif encompasses multiple discrete conformations, hydrogen bonds maintain the secondary structure and restrict the degrees of rotational freedom (e.g., see Figure 1 ). ${ }^{49}$
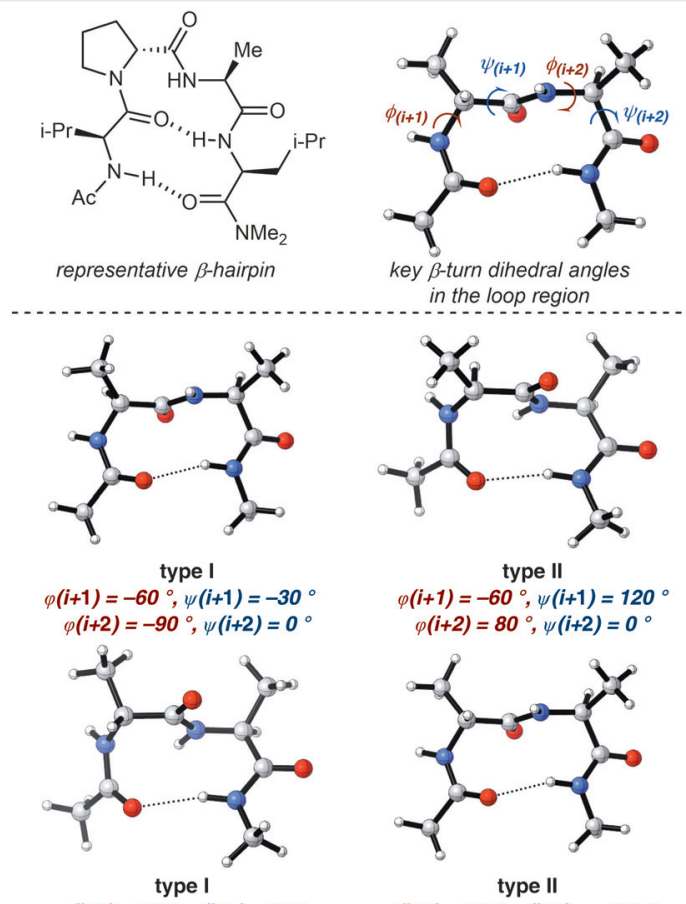

$\varphi(i+1)=60^{\circ}, \psi(i+1)=30^{\circ}$ $\varphi(i+2)=90^{\circ}, \psi(i+2)=0^{\circ}$

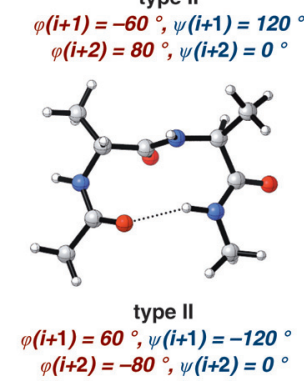

Figure 1 Representative dihedral angles for common $\beta$-turns

Although $\beta$ hairpin structures constrain the peptide into a more rigid structure, some flexibility has been shown to be important for catalysis. In the late 1990s and early 2000s, studies by Miller and coworkers regarding the octapeptide-catalyzed kinetic resolution of secondary alcohols revealed that NCIs between the catalyst and substrate combined with peptide dynamics led to high activity and selectivity. While the octapeptides used are structurally constrained through four hydrogen-bonding interactions, retaining some flexibility is required for selective catalysis. ${ }^{50}$ For example, for the kinetic resolution of substrates such as 21 (Scheme 12A), locking the catalyst conformation through ring-closing metathesis led to diminished selectivity (22 vs 23) even though the more constrained optimal octapeptidic catalyst $\mathbf{2 4}$ outperformed the best performing tetrapeptide $\mathbf{2 5}$ (Scheme 12B). ${ }^{50 a}$ Relative rate experiments revealed that, as opposed to destabilization, transition state 
A

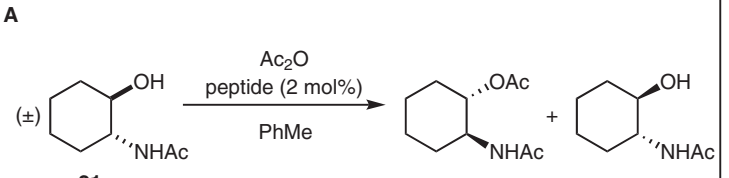

21
C

B<smiles>CCCC(N)C(=O)N1CCC[C@H]1C(=O)N[C@@H](C)C(=O)N[C@@H](C(N)=O)C(C)C</smiles><smiles>C=CC[C@H](N)C(=O)N[C@@H](CC=C)C(=O)N[C@@H](CC=C)C(=O)N[C@@H](Cc1cncn1C)C(N)=O</smiles>

22

$k_{\mathrm{r}}=20$

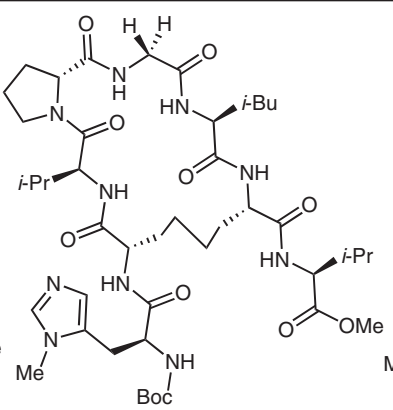

23

$k_{\text {rel }}=12$

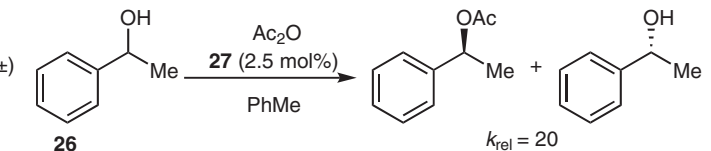

27 = Boc-Pmh-L (trt)Asn- ${ }^{-}$Val-L $($trt)His-DPhe-DVal-DVal-LAla-OMe

Scheme 12 (A) Peptide-catalyzed kinetic resolution. (B) Catalysts evaluated for the kinetic resolution shown in A. (C) Peptide-catalyzed kinetic resolution of secondary alcohols lacking an additional hydrogen-bonding functional group

stabilization, likely through multiple NCIs between catalyst and substrate, leads to the observed high levels of selectivity.

Further work expanded the substrate scope to secondary alcohols such as $\mathbf{2 6}$ that lack an additional hydrogenbonding functional group (Scheme 12C). ${ }^{50 \mathrm{~b}}$ The optimal catalyst for the previously described kinetic resolution afforded poor selectivity for this class of substrates. Subsequently, a split-and-pool catalyst library was used to identify an initial catalyst structure for further optimization. Lead catalyst $\mathbf{2 7}$ was then identified through a directed catalyst optimization followed by rescreening under homogeneous conditions. Mechanistic studies suggest that multiple NCIs between the catalyst and substrate are crucial for stabilizing the major diastereomeric transition state. ${ }^{50 \mathrm{~b}, \mathrm{c}}$ The peptides that can best engage in these NCIs are both the fastest and most selective catalysts. Furthermore, it is likely that these peptides employ a bifunctional activation mode for selectivity and that conformational dynamics could play a role throughout the catalytic cycle. ${ }^{50 c}$ More recent structural studies of short peptides by both Miller and Wennemers have further emphasized that these types of structurally constrained catalysts can adopt multiple conformations in solution and in the solid state, and that this flexibility is likely important for their catalytic activity and selectivity. ${ }^{51}$

While Miller and coworkers have developed a multitude of peptide-catalyzed transformations, an extensive mechanistic study of the atroposelective bromination of 3arylquinazolin-4(3H)-ones (quinazolinones) highlighted the flexibility of these catalysts. In 2015, Miller and coworkers first reported this transformation (Figure 2A) using lead catalyst $\mathbf{2 8}$ that bears a $\beta$-dimethylaminoalanine (Dmaa) catalytic residue. ${ }^{52}$ This transformation is highly ef- ficacious for a variety of quinazolinone substrates, affording enantioenriched products in up to 99:1 er. Interestingly, changes in the $i+2$ residue of the catalyst led to significant changes of the enantioselectivity, whereas similar alterations at the $i+3$ position resulted in only modest changes to the observed $\Delta \Delta G^{\ddagger}$. Alteration of the C-terminal protecting group from a methyl ester to a dimethyl amide also resulted in selectivity changes. Some especially intriguing differences include the substitution of the original Acpc residue (28) for Aib (29) at the $i+2$ residue, which results in a considerable loss of selectivity ( $90 \%$ ee vs $36 \%$ ee). However, replacing Acpc with Gly (30) results in similar levels of selectivity between these two catalysts ( $90 \%$ ee vs $82 \%$ ee, respectively). These experimental observations led to multiple structural studies of the tetrapeptidic catalysts evaluated for this transformation.51c,e From X-ray crystallization studies, wherein three different conformations (both type I' and type II', see Figures 1 and 2B) were observed for lead catalyst 28, it became apparent that even these carefully designed $\beta$-turn-containing tetrapeptides are conformationally dynamic, thus making both DFT and experimental analyses of these peptides more difficult. Computational approaches, particularly multivariate linear regression tools and molecular dynamics simulations, have been used to further study the atroposelective bromination of quinazolinones. ${ }^{53}$

Since these peptides readily interconvert between other conformations within the $\beta$-turn classification, computational analysis through transition-state computations would be quite difficult. ${ }^{54}$ Compounding this conformational challenge are the numerous possible weak, nondirectional NCIs that could compose the catalyst-substrate complex. $^{6 a, c, 7 a}$ One strategy to potentially address this challenge 
A
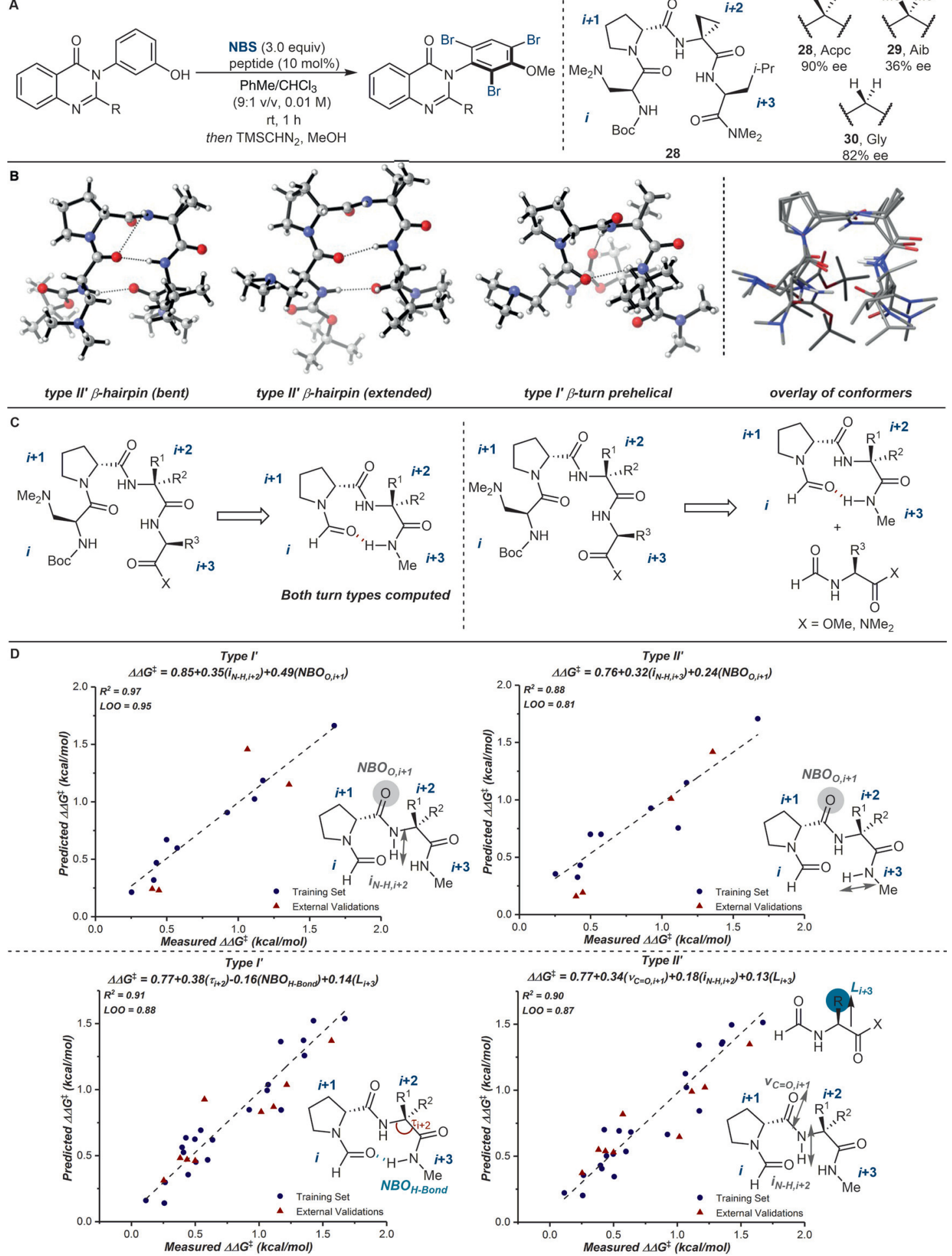

Figure 2 (A) Atroposelective bromination of quinazolinones and key results. (B) Three distinct conformations of lead catalyst 28. (C) Truncation schemes used. (D) Multivariate linear regression (MLR) models of the homologous i+2 series (top) and all data points (bottom) 

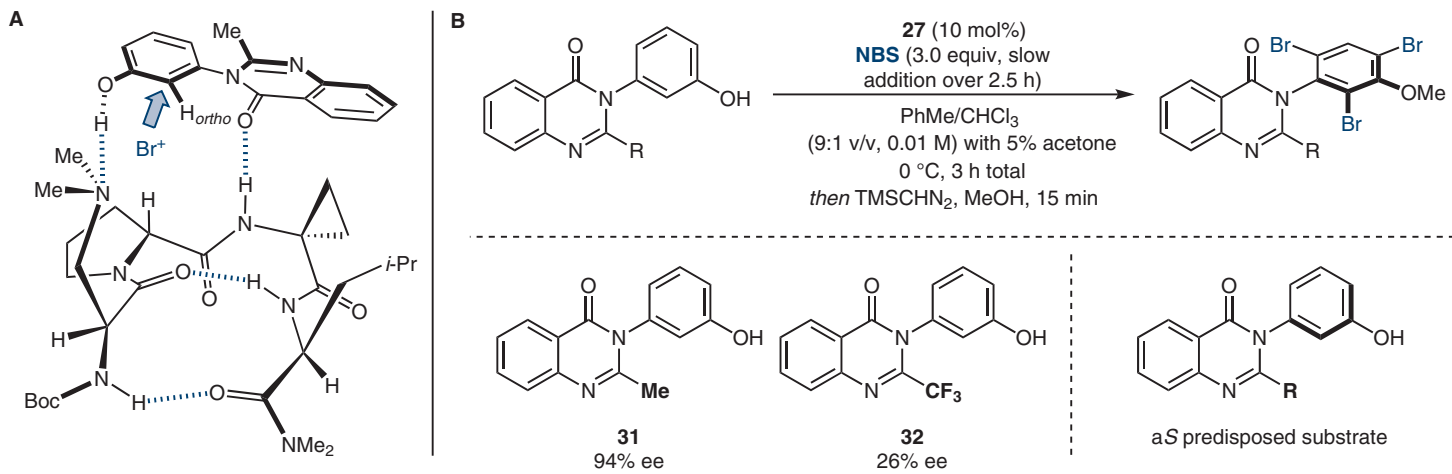

then $\mathrm{TMSCHN}_{2}, \mathrm{MeOH}, 15 \mathrm{~min}$
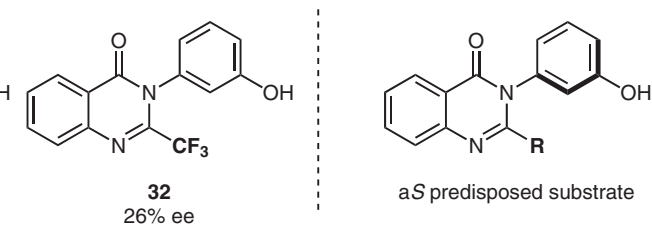

aS predisposed substrate

Scheme 13 (A) Two quinazolinones perform very differently in the atroposelective bromination reaction. (B) The proposed binding mode between catalyst and substrates orients the phenol ring such that the first bromination occurs at the shown ortho position

and gain insight into key structural features that influence selectivity is to develop structure-function relationships through the application of modern physical organic tools to relate the reaction output(s) to computed structural parameters. ${ }^{53 a, 55}$

Miller, Sigman, and coworkers applied this type of analysis to gain insight into which conformation is more responsible for the observed selectivity and to gain insight into key catalyst features to inform future catalyst development. ${ }^{53 a}$ Because the most significant variations in selectivity were observed when altering the $i+2$ residue, an initial truncation design was employed to reduce the conformational space and focus on changes at the $i+2$ residue (Figure 2C). Both major turn types (I' and II') were computed (M062X/def2-TZVP) and parameters, including IR stretching frequencies, natural bond orbital (NBO) charges, ${ }^{56}$ Sterimol parameters, ${ }^{57}$ and dihedral angles, were extracted. Within the homologous $i+2$ series, two different multivariate linear regression models were developed for each observed turn type (Figure 2D, top). The parameters in both models suggest that the Lewis basic oxygen at the $i+1$ residue may assist in delivering the electropositive bromine to the ortho position of the phenol, thus setting the axis of chirality. ${ }^{58}$ Moreover, there is likely a two-prong hydrogen-bonding interaction between the quinazolinone and catalyst, consistent with the experimentally proposed binding model (Scheme 13A). ${ }^{52,53}$ Finally, in the type II' case, the $\beta$-turn-defining hydrogen bond is important for selectivity. Because the parameters used in these models for the $i+2$ series are not correlated with each other, this suggests that both of these turn types are catalytically active. ${ }^{53 a}$ Following the successful identification of correlations for the truncate, the effects of the $i+3$ residue and $C$-terminal protecting group were also considered. ${ }^{53 a}$ To maintain a low degree of conformational complexity to reduce the computational cost, the $i+3$ residue was computed separately and parameters obtained from these ground state structures were used as additional descriptors within the existing parameter sets for both type I' and II' conformations. Following multivariate linear regression with this expanded descriptor set, two additional models were identified, again derived from each of the two major $\beta$-turn types (Figure 2D, bottom). The only conserved parameter being $L_{\mathrm{i}+3}$, the length of the $i+3$ residue, implying a similar effect of the steric bulk at this particular position for each major conformer type. The parameters used for the models when incorporating $i+3$ represent comparable structural characteristics of the peptide catalysts to those identified within the $i+2$ series. Therefore, the multivariate linear regression models developed for both the homologous $i+2$ series and the entire experimental data set suggest that the ability of tetrapeptidic catalysts to access multiple conformations may be an important feature for effective catalysis. Although it is a possibility that one conformation is predominantly responsible for the observed selectivity, it is more likely that multiple conformations contribute to a more complex transition-state ensemble.

Another effective computational approach for the analysis of these flexible peptidic systems is through molecular dynamics simulations and multidimensional clustering analysis. ${ }^{5 \mathrm{~b}}$ Jorgensen and coworkers reported their work analyzing the atroposelective bromination of quinazolinones (Scheme 13A), seeking to explore substrate-induced peptide conformational changes and the contributions of the multiple observed conformations to catalysis. Of particular interest was understanding the differing performances of quinazolinone $\mathbf{3 1}$ versus trifluoromethyl-containing quinazolinone 32, as the brominated product of $\mathbf{3 2}$ was only obtained in $26 \%$ ee. In the absence of substrate, the dominant conformation of catalyst $\mathbf{2 8}$ was a type I' $\beta$-turn, comprising $75 \%$ of the population when simulated in benzene, which mimics the reaction conditions. Upon introduction of substrate $\mathbf{3 1}$ in both predisposed $S$ and aR configurations, the conformational distribution changed significantly. When catalyst $\mathbf{2 8}$ was simulated in the presence of aS-quinazolinone 31, which leads to the major experimentally observed enantiomer, the type II' conformation comprised $75 \%$ of the population, whereas the previously 
dominant type I' conformation decreased to $19 \%$. When the corresponding $\mathrm{a} R$ substrate is introduced, the conformation distribution becomes much more heterogeneous. Similar to the mismatched substrate, when aS trifluoromethyl-containing quinazolinone $\mathbf{3 2}$ is used, it has a much weaker interaction with peptide $\mathbf{2 8}$ than quinazolinone $\mathbf{3 1}$, resulting in less of a population change. In other words, the peptide conformation distribution more closely resembles that of 28 in the absence of substrate, where multiple conformations contribute to the overall population. Although quinazolinones $\mathbf{3 1}$ and $\mathbf{3 2}$ bind in a similar manner to peptide 28 through NCIs, the inherently weaker H-bonding interaction between $\mathbf{3 2}$ and $\mathbf{2 8}$ leads to less of a substrate-induced conformational shift. Importantly, these computational results are corroborated by NMR studies. Throughout the molecular dynamics simulations, it became apparent that even though some catalyst rigidity is required in the transition state, conformational dynamics are crucial for selectivity.

The importance of catalyst dynamics has also been noted in various peptide-catalyzed transformations examined by Wennemers and coworkers. ${ }^{59}$ Using a DPro/Pro/Xaa motif, they recently reported highly stereoselective conjugate additions of aldehydes to nitroalkenes (Scheme 14A). ${ }^{60}$ Initial mechanistic studies revealed that enamine intermediate $\mathbf{3 4}$ plays a key role in the rate- and enantiodetermining step: $\mathrm{C}-\mathrm{C}$ bond formation between enamine $\mathbf{3 4}$ and the nitroalkene. ${ }^{61}$ However, these initial kinetic studies could not uncover the hypothesized importance of catalyst and enamine flexibility. Subsequently, through the use of experimental NMR techniques, including analysis of nuclear Overhauser effects (NOEs), residual dipolar couplings (RDCs) and $J$-couplings, in conjunction with X-ray structures and computational studies, the authors further investigated the conformational dynamics of both $\mathbf{3 3}$ and $\mathbf{3 4 . 5 1 \mathrm { d }}$ NMR studies of catalyst $\mathbf{3 3}$ revealed that the structure assumes a relatively rigid type I $\beta$-turn in solution, with stabilizing, structure-defining hydrogen-bonding interactions shown in Figure 1.

Furthermore, the glutamic acid side chain, which could assume a number of conformations, is relatively restricted due to a favorable hydrogen-bonding interaction with the DPro residue in the ground state (Scheme 14B). In contrast, similar studies on the enamine $\mathbf{3 4}$ revealed that this rigid secondary structure is destabilized. Moreover, the glutamic acid side chain is significantly more flexible, as the H-bonding interaction between glutamic acid and ${ }^{\text {PPro must disap- }}$ pear upon formation of the enamine. The carboxylic acid is not entirely innocent, as a change in the conformation of this residue also results in a more global conformational change. The enamine is then better able to adapt to the presence of the nitroolefin. Thus, a relatively rigid peptide is transformed into a much more flexible enamine intermediate. This conformational study of the key intermediate $\mathbf{3 4}$,

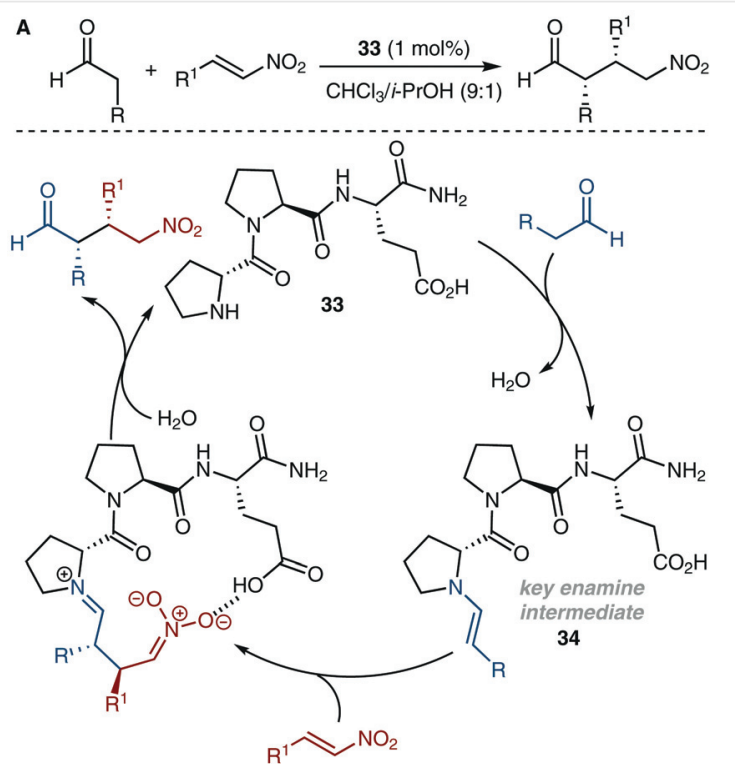

rate- and enantiodeterming step

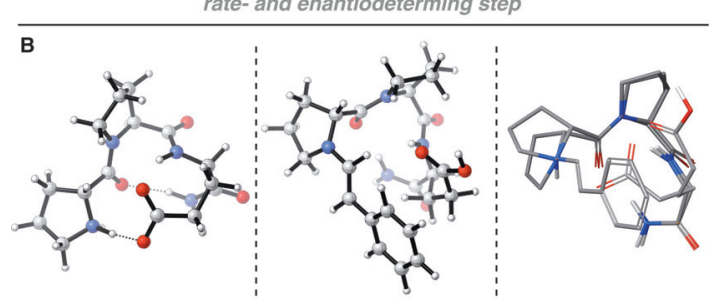

Scheme 14 (A) Conjugate addition and its catalytic cycle. (B) Ground state conformations of the catalyst (left), enamine (center), and the overlay of catalyst and enamine (right)

as well as catalyst 33, allowed for a deeper understanding of the underlying reasons for the high levels of selectivity and catalytic activity. Peptide conformational dynamics are important during catalysis, and a balance between rigidity and flexibility means that the peptide can adapt to stabilize the structures of transition states and intermediates throughout the catalytic cycle while simultaneously providing a defined chiral environment, thus enhancing selectivity.

In contrast to the peptides utilized by both Wennemers and Miller, in 2008, Schreiner and coworkers reported a kinetic resolution of trans-cycloalkane-1,2-diols (e.g., 35) using a lipophilic peptide catalyst 36 (Scheme $15 \mathrm{~A}$ ). ${ }^{62}$ This peptide was designed not based on secondary structure, but instead to maximize solubility in organic solvents, mimicking the 'pocket-like' nature of an enzyme active site. $^{62,63}$ In fact, one reason for the high chemoselectivity and stereoselectivity might be that $(R, R)-\mathbf{3 5}$ fits well in this pocket with a relatively strong stabilizing $\mathrm{H}$-bond, which was later validated by NMR experiments. ${ }^{63,64}$ In contrast, any other potential stereoisomer exhibits weaker catalystsubstrate $\mathrm{H}$-bonding interactions. Computational analysis using molecular dynamics and DFT calculations revealed 
A
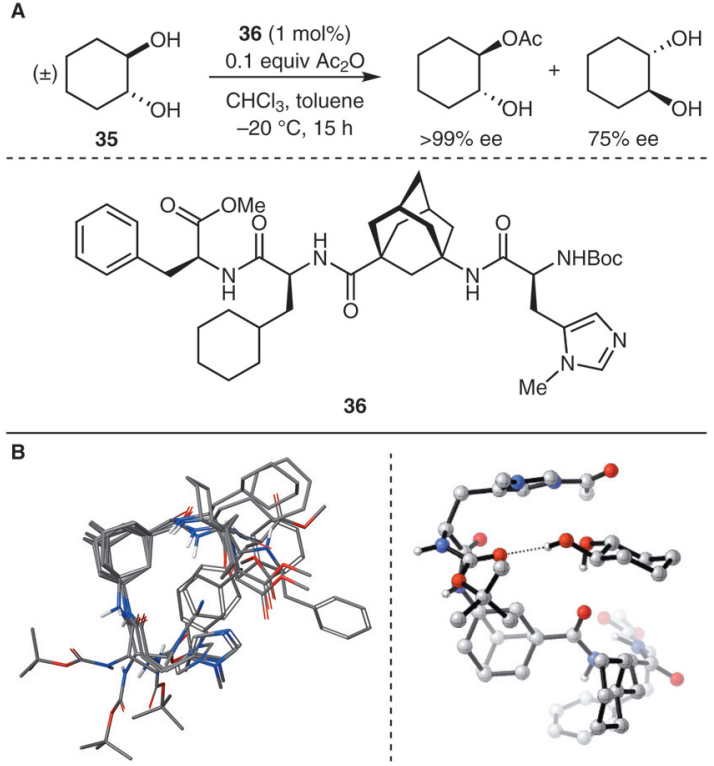

Scheme 15 (A) Peptide-catalyzed kinetic resolution. (B) Overlay of the four lowest energy catalyst conformations (left) and likely transition state (right). Nonpolar hydrogens omitted for clarity

that additional stabilizing interactions between the substrate and acylated catalyst include dispersion interactions with the cyclohexyl group of cyclohexylalanine and hydrogen bonding with nearby carbonyls. ${ }^{6 b, 63}$ Subsequent structural studies were performed using NMR techniques in conjunction with computational studies to further elucidate conformational features and how they influence catalysis. ${ }^{64}$ From NMR studies predominantly using NOE and RDC experiments, an ensemble of conformations was identified. By performing computations and relating rotating frame Overhauser effect (ROE) contacts to those from structural simulations, four key conformers were identified that all adopt the hypothesized 'pocket-like' enzyme mimetic structure. NMR studies of the peptide-substrate complex identified a population shift of the peptide conformation upon introduction of either $(R, R)-35$ or $(S, S)-\mathbf{3 5}$, especially the catalytic histidine residue. Importantly, this is more significant in the case of $(R, R)-\mathbf{3 5}$, the favored enantiomer for acylation. Also, by using homonuclear decoupling to simplify the aliphatic region of the NMR spectrum, the dispersive interactions between substrate and cyclohexylalanine were experimentally confirmed. Thus, through experiment and computation, it was determined that conformational dynamics are important for the selectivity of the designed lipophilic oligopeptide used for the acylation of trans-cyclohexyl-1,2-diols.

Although peptidic catalysts were originally designed to constrain rotational degrees of freedom, recent structural studies by Miller, Schreiner, and Wennemers among others have demonstrated that peptide catalysts are more conformationally complex than initially anticipated. Moreover, catalyst flexibility likely contributes to effective catalysis, with the possibility of multiple conformers contributing to transition-state ensembles leading to products.

\section{Conclusion}

Initial work on asymmetric catalysis focused on incorporating rigid motifs within a catalyst, resulting in stereochemical models that almost exclusively invoked steric repulsion as the underlying reason for the difference in energy between two different diastereomeric transition states. However, recent work has demonstrated that, similar to enzymes, attractive, dynamic, and cooperative NCIs may be as, or even more, important than steric repulsion for low molecular weight asymmetric catalysts. Flexible catalysts may be able to arrange themselves in an induced-fit-type mechanism to maximize the effect of these interactions throughout the course of the catalytic cycle. Although the most evidence exists for the importance of conformational dynamics for peptidic catalysts, a variety of other catalyst classes have been demonstrated to benefit from conformational flexibility, including tropos ligands, cinchona alkaloids, and HBD catalysts. We anticipate as the field continues to evolve that some level of conformational flexibility will be incorporated into the design of new asymmetric catalysts.

\section{Funding Information}

J.M.C. acknowledges the support of the NSF Graduate Research Fellowship Program. M.S.S. thanks the NIH (1 R01 GM121383) for supporting this work.

\section{Acknowledgment}

J.M.C. would like to thank Dr. Anthony J. Metrano and Elizabeth A. Stone for useful discussions.

\section{References}

(1) (a) Smith, A. J. T.; Müller, R.; Toscano, M. D.; Kast, P.; Hellinga, H. W.; Hilvert, D.; Houk, K. N. J. Am. Chem. Soc. 2008, 130, 15361. (b) Garcia-Viloca, M.; Gao, J.; Karplus, M.; Truhlar, D. G. Science 2004, 303, 186. (c) Warshel, A.; Sharma, P. K.; Kato, M.; Xiang, Y.; Liu, H. B.; Olsson, M. H. M. Chem. Rev. 2006, 106, 3210.

(2) Bahar, I.; Chennubhotla, C.; Tobi, D. Curr. Opin. Struct. Biol. 2007, 17, 633.

(3) Fischer, E. Ber. Dtsch. Chem. Ges. 1894, 27, 3189.

(4) (a) Koshland, D. E. Angew. Chem. Int. Ed. 1994, 33, 2375. (b) Hong, C. M.; Kaphan, D. M.; Bergman, R. G.; Raymond, K. N.; Toste, F. D. J. Am. Chem. Soc. 2017, 139, 8013. (c) Monod, J.; Wyman, J.; Changeux, J. P. J. Mol. Biol. 1965, 12, 88.

(5) (a) Austin, J. F.; MacMillan, D. W. C. J. Am. Chem. Soc. 2002, 124, 1172. (b) Corey, E. J.; Ishihara, K. Tetrahedron Lett. 1992, 33, 6807. (c) Trost, B. M.; Machacek, M. R.; Aponick, A. Acc. Chem. Res. 2006, 39, 747. (d) Noyori, R.; Tokunaga, M.; Kitamura, M. Bull. Chem. Soc.Jpn. 1995, 68, 36. 
(6) (a) Knowles, R. R.; Jacobsen, E. N. Proc. Natl. Acad. Sci. U.S.A. 2010, 107, 20678. (b) Wagner, J. P.; Schreiner, P. R. Angew. Chem. Int. Ed. 2015, 54, 12274. (c) Davis, H. J.; Phipps, R. J. Chem. Sci. 2017, 8, 864 .

(7) (a) Toste, F. D.; Sigman, M. S.; Miller, S. J. Acc. Chem. Res. 2017, 50, 609. (b) Neel, A. J.; Hilton, M. J.; Sigman, M. S.; Toste, F. D. Nature 2017, 543, 637.

(8) Ōki, M. Recent Advances in Atropisomerism, In Topics in Stereochemistry; Allinger, N. L.; Eliel, E. L.; Wilen, S. H., Ed.; John Wiley \& Sons: New York, 1983, 1.

(9) (a) Noyori, R.; Takaya, H. Acc. Chem. Res. 1990, 23, 345. (b) Yoon, T. P.; Jacobsen, E. N. Science 2003, 299, 1691. (c) Shimizu, H.; Nagasaki, I.; Saito, T. Tetrahedron 2005, 61, 5405. (d) Ohkuma, T.; Kurono, N. BINAP, In Privileged Chiral Ligands and Catalysts; Zhou, Q.-L., Ed.; Wiley-VCH: Weinheim, 2011, Chap. 1,. (e) Shibasaki, M.; Matsunaga, S. BINOL, In Privileged Chiral Ligands and Catalysts; Zhou, Q.-L., Ed.; Wiley-VCH: Weinheim, 2011, Chap. 8, 295.

(10) Noyori, R.; Ohkuma, T.; Kitamura, M.; Takaya, H.; Sayo, N.; Kumobayashi, H.; Akutagawa, S. J. Am. Chem. Soc. 1987, 109, 5856.

(11) Ohta, T.; Takaya, H.; Noyori, R. Inorg. Chem. 1988, 27, 566.

(12) Clayden, J. Chem. Commun. 2004, 127.

(13) (a) Mikami, K.; Aikawa, K.; Yusa, Y.; Jodry, J. J.; Yamanaka, M. Synlett 2002, 1561. (b) Aikawa, K.; Mikami, K. Chem. Commun. 2012, 48, 11050. (c) Storch, G.; Maier, F.; Wessig, P.; Trapp, O. Eur. J. Org. Chem. 2016, 5123.

(14) (a) Mikami, K.; Matsukawa, S. Nature 1997, 385, 613. (b) Faller, J. W.; Lavoie, A. R.; Parr, J. Chem. Rev. 2003, 103, 3345.

(15) Mikami, K.; Korenaga, T.; Terada, M.; Ohkuma, T.; Pham, T.; Noyori, R. Angew. Chem. Int. Ed. 1999, 38, 495.

(16) Storch, G.; Trapp, O. Angew. Chem. Int. Ed. 2015, 54, 3580.

(17) Siebert, M.; Storch, G.; Rominger, F.; Trapp, O. Synthesis 2017, 49, 3485.

(18) Pamies, O.; Dieguez, M. Chem. Rec. 2016, 16, 2460.

(19) (a) Bellini, R.; Magre, M.; Biosca, M.; Norrby, P. O.; Pamies, O.; Dieguez, M.; Moberg, C. ACS Catal. 2016, 6, 1701. (b) Coll, M.; Pamies, O.; Dieguez, M. Org. Lett. 2014, 16, 1892. (c) Dieguez, M.; Pamies, O. Acc. Chem. Res. 2010, 43, 312. (d) Margalef, J.; Coll, M.; Norrby, P. O.; Pamies, O.; Dieguez, M. Organometallics 2016, 35, 3323. (e) Raluy, E.; Parmies, O.; Dieguez, M. Adv. Synth. Catal. 2009, 351, 1648.

(20) Pamies, O.; Dieguez, M.; Claver, C. J. Am. Chem. Soc. 2005, 127, 3646.

(21) (a) Bausch, C. C.; Pfaltz, A. PHOX Ligands, In Privileged Chiral Ligands and Catalysts; Zhou, Q.-L., Ed.; Wiley-VCH: Weinheim, 2011, Chap. 6, 221. (b) Trost, B. M. Acc. Chem. Res. 1996, 29, 355. (c) Helmchen, G.; Pfaltz, A. Acc. Chem. Res. 2000, 33, 336.

(22) Masdeu-Bulto, A. M.; Dieguez, M.; Martin, E.; Gomez, M. Coord. Chem. Rev. 2003, 242, 159.

(23) Bredig, G.; Fiske, P. Biochem. Z 1912, 46, 7.

(24) (a) Connon, S. J. Chem. Commun. 2008, 2499. (b) Li, H.; Chen, Y.; Deng, L. Cinchona Alkaloids, In Privileged Chiral Ligands and Catalysts; Zhou, Q.-L., Ed.; Wiley-VCH: Weinheim, 2011, Chap. 10, 361. (c) Marcelli, T.; Hiemstra, H. Synthesis 2010, 1229. (d) Tian, S. K.; Chen, Y. G.; Hang, J. F.; Tang, L.; McDaid, P.; Deng, L. Acc. Chem. Res. 2004, 37, 621.

(25) Dijkstra, G. D. H.; Kellogg, R. M.; Wynberg, H.; Svendsen, J. S.; Marko, I.; Sharpless, K. B. J. Am. Chem. Soc. 1989, 111, 8069.

(26) Urakawa, A.; Meier, D. M.; Rugger, H.; Baiker, A. J. Phys. Chem. A 2008, $112,7250$.

(27) Seeman, J. I. Chem. Rev. 1983, 83, 83.

(28) Whitesell, J. K. Chem. Rev. 1989, 89, 1581.
(29) (a) Corey, E. J.; Noe, M. C. J. Am. Chem. Soc. 1993, 115, 12579. (b) Corey, E. J.; Noe, M. C. J. Am. Chem. Soc. 1996, 118, 11038.

(30) Braje, W.; Frackenpohl, J.; Langer, P.; Hoffmann, H. M. R. Tetrahedron 1998, 54, 3495.

(31) Tanzer, E. M.; Schweizer, W. B.; Ebert, M. O.; Gilmour, R. Chem. Eur. J. 2012, 18, 2006.

(32) Li, H. M.; Wang, Y.; Tang, L.; Deng, L. J. Am. Chem. Soc. 2004, 126, 9906.

(33) Li, H. M.; Wang, Y.; Tang, L.; Wu, F. H.; Liu, X. F.; Guo, C. Y.; Foxman, B. M.; Deng, L. Angew. Chem. Int. Ed. 2005, 44, 105.

(34) (a) Chen, Y. G.; Deng, L. Abstr. Pap. Am. Chem. Soc. 2002, 224, U249. (b) Chen, Y. G.; Deng, L. J. Am. Chem. Soc. 2001, 123, 11302. (c) Chen, Y. G.; McDaid, P.; Deng, L. Chem. Rev. 2003, 103, 2965. (d) Chen, Y. G.; Tian, S. K.; Deng, L. J. Am. Chem. Soc. 2000, 122, 9542. (e) Hang, J. F.; Deng, L. Synlett 2003, 1927. (f) Hang, J. F.; Li, H. M.; Deng, L. Org. Lett. 2002, 4, 3321. (g) Hang, J. F.; Tian, S. K.; Tang, L.; Deng, L. J. Am. Chem. Soc. 2001, 123, 12696.

(35) Li, H. M.; Liu, X. F.; Wu, F. H.; Tang, L. A.; Deng, L. Proc. Natl. Acad. Sci. U.S.A. 2010, 107, 20625.

(36) (a) Doyle, A. G.; Jacobsen, E. N. Chem. Rev. 2007, 107, 5713. (b) Schreiner, P. R. Chem. Soc. Rev. 2003, 32, 289.

(37) Taylor, M. S.; Jacobsen, E. N. Angew. Chem. Int. Ed. 2006, 45, 1520.

(38) (a) Sohtome, Y.; Nagasawa, K. Chem. Commun. 2012, 48, 7777. (b) Sohtome, Y.; Nagasawa, K. Synlett 2010, 1.

(39) Sohtome, Y.; Tanaka, S.; Takada, K.; Yamaguchi, T.; Nagasawa, K. Angew. Chem. Int. Ed. 2010, 49, 9254.

(40) Eyring, H. J. Chem. Phys. 1935, 3, 107.

(41) (a) Kato, M.; Hirao, S.; Nakano, K.; Sato, M.; Yamanaka, M.; Sohtome, Y.; Nagasawa, K. Chem. Eur. J. 2015, 21, 18606. (b) Sohtome, Y.; Shin, B.; Horitsugi, N.; Takagi, R.; Noguchi, K.; Nagasawa, K. Angew. Chem. Int. Ed. 2010, 49, 7299.

(42) Buschmann, H.; Scharf, H. D.; Hoffmann, N.; Esser, P. Angew. Chem. Int. Ed. 1991, 30, 477.

(43) Klausen, R. S.; Kennedy, C. R.; Hyde, A. M.; Jacobsen, E. N. J. Am. Chem. Soc. 2017, 139, 12299.

(44) Klausen, R. S.; Jacobsen, E. N. Org. Lett. 2009, 11, 887.

(45) (a) Eder, U.; Sauer, G.; Wiechert, R. Angew. Chem. Int. Ed. 1971, 10, 496. (b) Eder, U.; Sauer, G.; Wiechert, R. German Patent 2014757, 1971. (c) Hajos, Z. G.; Parrish, D. R. German Patent 2102623, 1971.

(46) (a) Davie, E. A. C.; Mennen, S. M.; Xu, Y.; Miller, S. J. Chem. Rev. 2007, 107, 5759. (b) Miller, S. J. Acc. Chem. Res. 2004, 37, 601. (c) Wennemers, H. Chem. Commun. 2011, 47, 12036. (d) Wennemers, H. Biopolymers 2013, 100, 241.

(47) Privileged Chiral Ligands and Catalysts; Zhou, Q.-L., Ed.; WileyVCH: Weinheim, 2011.

(48) (a) Gardner, R. R.; Gellman, S. H. J. Am. Chem. Soc. 1995, 117, 10411. (b) Haque, T. S.; Little, J. C.; Gellman, S. H. J. Am. Chem. Soc. 1996, 118, 6975.

(49) Wilmot, C. M.; Thornton, J. M. J. Mol. Biol. 1988, 203, 221.

(50) (a) Jarvo, E. R.; Copeland, G. T.; Papaioannou, N.; Bonitatebus, P. J.; Miller, S. J. J. Am. Chem. Soc. 1999, 121, 11638. (b) Copeland, G. T.; Miller, S. J. J. Am. Chem. Soc. 2001, 123, 6496. (c) Fierman, M. B.; O'Leary, D. J.; Steinmetz, W. E.; Miller, S. J. J. Am. Chem. Soc. 2004, 126, 6967.

(51) (a) Abascal, N. C.; Metrano, A. J.; Lichtor, P. A.; Giuliano, M. W.; Miller, S. J. Protein Sci. 2016, 25, 150. (b) Abascal, N. C.; Miller, S. J. Org. Lett. 2016, 18, 4646. (c) Metrano, A. J.; Abascal, N. C.; Mercado, B. Q.; Paulson, E. K.; Hurtley, A. E.; Miller, S. J. J. Am. Chem. Soc. 2017, 139, 492. (d) Rigling, C.; Kisunzu, J. K.; Duschmale, J.; Haussinger, D.; Wiesner, M.; Ebert, M. O.; 
Wennemers, H. J. Am. Chem. Soc. 2018, 140, 10829. (e) Metrano, A. J.; Abascal, N. C.; Mercado, B. Q.; Paulson, E. K.; Miller, S. J. Chem. Commun. 2016, 52, 4816.

(52) Diener, M. E.; Metrano, A. J.; Kusano, S.; Miller, S. J. J. Am. Chem. Soc. 2015, 137, 12369.

(53) (a) Crawford, J. M.; Stone, E. A.; Metrano, A. J.; Miller, S. J.; Sigman, M. S. J. Am. Chem. Soc. 2018, 140, 868. (b) Yan, X. C.; Metrano, A. J.; Robertson, M. J.; Abascal, N. C.; Tirado-Rives, J.; Miller, S. J.; Jorgensen, W. L. ACS Catal. 2018, 8, 9968.

(54) Thiel, W. Angew. Chem. Int. Ed. 2014, 53, 8605.

(55) (a) Reid, J. P.; Sigman, M. S. Nat. Rev. Chem. 2018, 2, 290. (b) Sigman, M. S.; Harper, K. C.; Bess, E. N.; Milo, A. Acc. Chem. Res. 2016, 49, 1292. (c) Santiago, C. B.; Guo, J. Y.; Sigman, M. S. Chem. Sci. 2018, 9, 2398.

(56) Glendening, E. D.; Reed, A. E.; Carpenter, J. E.; Weinhold, F. NBO Version 3.1.

(57) Verloop, A. Drug Design; Academic Press: New York, 1976.

(58) (a) Denmark, S. E.; Beutner, G. L. Angew. Chem. Int. Ed. 2008, 47, 1560. (b) Denmark, S. E.; Burk, M. T. Proc. Natl. Acad. Sci. U.S.A. 2010, 107, 20655.
(59) (a) Schnitzer, T.; Wennemers, H. J. Am. Chem. Soc. 2017, 139, 15356. (b) Schnitzer, T.; Wiesner, M.; Krattiger, P.; Revell, J. D.; Wennemers, H. Org. Biomol. Chem. 2017, 15, 5877.

(60) (a) Wiesner, M.; Neuburger, M.; Wennemers, H. Chem. Eur. J. 2009, 15, 10103. (b) Wiesner, M.; Revell, J. D.; Wennemers, H. Angew. Chem. Int. Ed. 2008, 47, 1871. (c) Wiesner, M.; Revell, J. D.; Tonazzi, S.; Wennemers, H. J. Am. Chem. Soc. 2008, 130, 5610.

(61) (a) Wiesner, M.; Upert, G.; Angelici, G.; Wennemers, H. J. Am. Chem. Soc. 2010, 132, 6. (b) Bachle, F.; Duschmale, J.; Ebner, C.; Pfaltz, A.; Wennemers, H. Angew. Chem. Int. Ed. 2013, 52, 12619. (c) Duschmale, J.; Wiest, J.; Wiesner, M.; Wennemers, H. Chem. Sci. 2013, 4, 1312.

(62) Müller, C. E.; Wanka, L.; Jewell, K.; Schreiner, P. R. Angew. Chem. Int. Ed. 2008, 47, 6180.

(63) Müller, C. E.; Zell, D.; Hrdina, R.; Wende, R. C.; Wanka, L.; Schuler, S. M. M.; Schreiner, P. R. J. Org. Chem. 2013, 78, 8465.

(64) Prochazkova, E.; Kolmer, A.; Ilgen, J.; Schwab, M.; Kaltschnee, L.; Fredersdorf, M.; Schmidts, V.; Wende, R. C.; Schreiner, P. R.; Thiele, C. M. Angew. Chem. Int. Ed. 2016, 55, 15754. 